\title{
STOL Performance of Cal Poly's AMELIA
}

\author{
Jonathan A. Lichtwardt ${ }^{*}$, Eric N. Paciano ${ }^{*}$, and David D. Marshall ${ }^{\dagger}$ \\ California Polytechnic State University, San Luis Obispo, CA, 93407-0352 \\ Kristina K. Jameson ${ }^{\ddagger}$ \\ Space Systems/Loral, Palo Alto, CA, 94303
}

\begin{abstract}
Results from Cal Poly's recent wind tunnel test in the 40 - by 80 -foot test section at the National Full-Scale Aerodynamics Complex (NFAC) at NASA Ames Research Center are presented. AMELIA, the Advanced Model for Extreme Lift and Improved Aeroacoustics, is the first full-span cruise efficient short take-off and landing (CESTOL) model incorporating leading- and trailing-edge blowing wing circulation control and over-the-wing mounted turbine propulsion simulators (TPS) to date. Testing of the 10 foot span model proved successful and was the result of a 5-year NASA Fundamental Aeronautics Program Research Announcement. All of the results associated with Cal Poly's effort will be available in an open-source validation database with the goal of advancing the state-of-the-art in prediction capabilities for modeling aircraft with next generation technologies, focusing on NASA's N+2 generation goals. The model's modular design allowed for testing of 4 major configurations. Results from all configurations are presented. Test data shows drastic improvements in performance are obtained when incorporating leading edge blowing. Wing stall can be delayed to more than $25^{\circ}$ angle of attack at lift coefficients exceeding six. Without the introduction of leading edge blowing to increase boundary layer momentum and maintain flow attachment around the leading edge, STOL performance suffers. Similar runs for trailing edge-only blowing show a reduction in maximum lift coefficient to three with stall occurring at zero angle of attack. Testing at multiple engine pylon heights allowed for the highly coupled propulsion and flow control system to be characterized.
\end{abstract}

$\begin{array}{ll}C_{D} & =\text { drag coefficient } \\ C_{L} & =\text { lift coefficient } \\ C_{m} & =\text { pitching moment coefficient } \\ C_{P} & =\text { pressure coefficient } \\ C_{P}{ }^{*} & =\text { critical pressure coefficient } \\ C_{T} & =\text { thrust coefficient } \\ C_{\mu} & =\text { momentum coefficient } \\ C, C & =\text { wing chord, inches } \\ D & =\text { fan diameter, inches } \\ h & =\text { local slot height, inches } \\ K & =\text { order of least-squares curve fit } \\ M & =\text { Mach number } \\ \dot{m} & =\text { mass flow rate, lb } \mathrm{m} / \mathrm{sec} \\ P & =\text { pressure, psi } \\ q & =\text { dynamic pressure, psf } \\ R & =\text { gas constant, } 1716.59 \mathrm{ft}-\mathrm{lb}_{\mathrm{f}} / \mathrm{slug}-\mathrm{R} \\ R e & =\text { Reynolds number } \\ R^{2} & =\text { coefficient of determination }\end{array}$

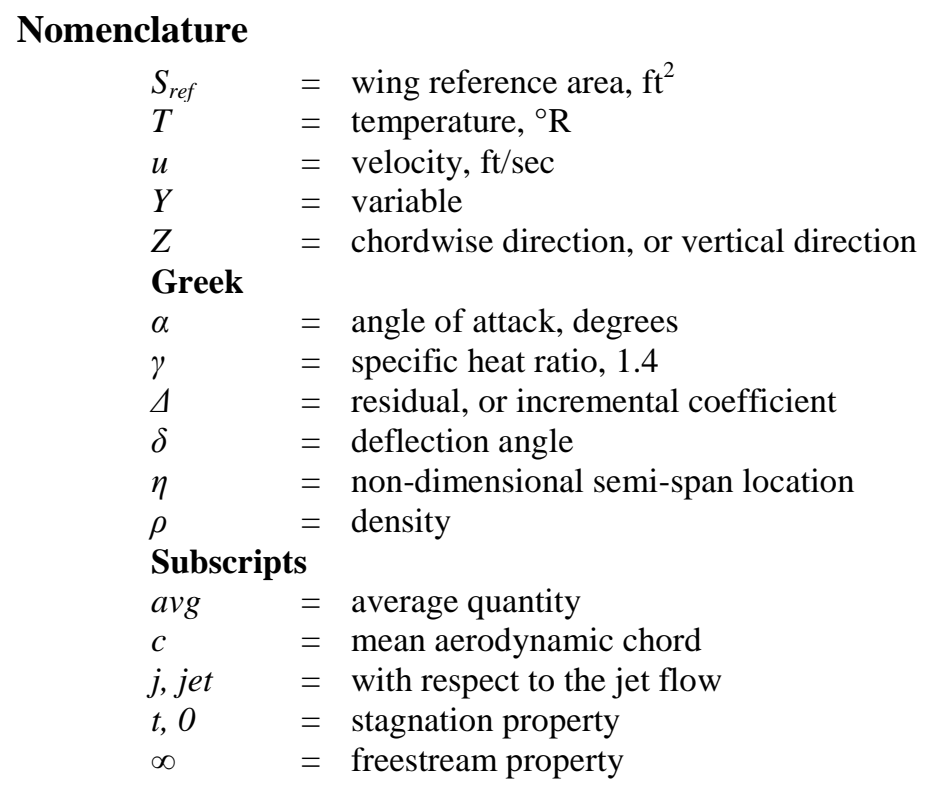

\footnotetext{
* Graduate Student, Aerospace Engineering Department, Student Member AIAA.

${ }^{\dagger}$ Associate Professor, Aerospace Engineering Department, Senior Member AIAA.

${ }^{\ddagger}$ Propulsion Specialist, Member AIAA.
} 


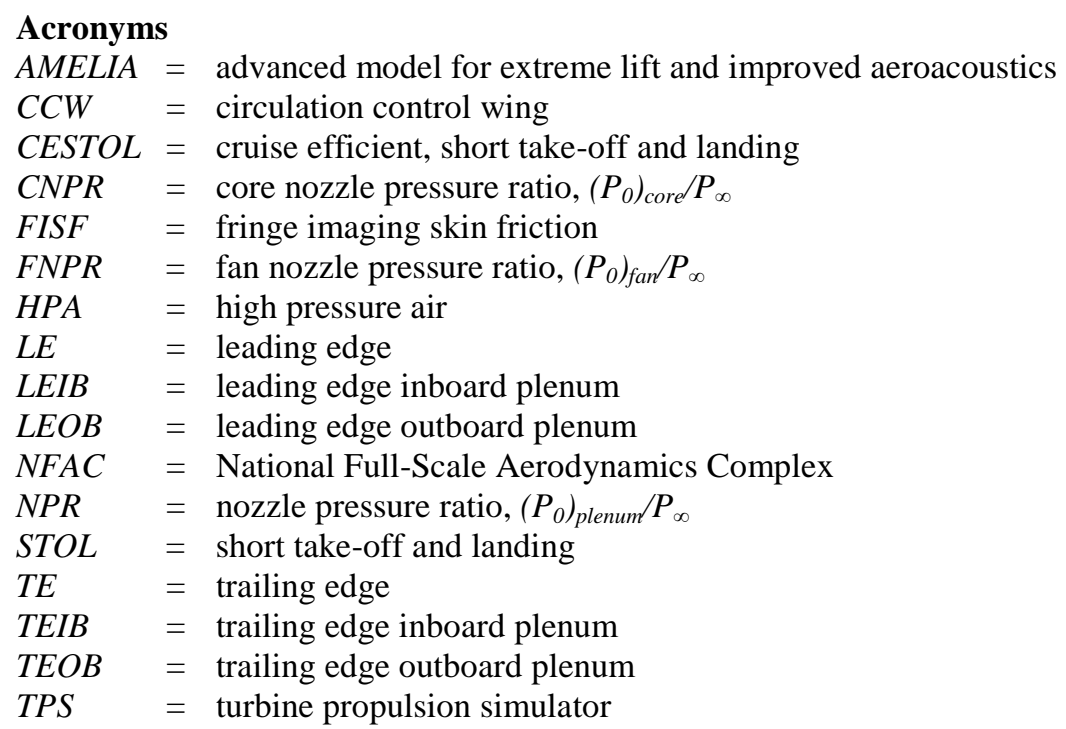

\section{Introduction}

$\mathrm{W}$ ITH the advent of the Environmentally Responsible Aviation Project (ERA), NASA has showed its continued support for the need to research technologies that will enable the next generation of regional commercial transports to fly quieter, on less fuel, and produce fewer emissions. Increased congestion at airports, and noise regulations have prompted NASA to evaluate how short take-off and landing (STOL) capabilities can be integrated into cruise efficient geometries, enabling larger airplanes to operate within the existing infrastructure of smaller civilian airports $^{1}$. One specific project, with goals similar to those of ERA, is a NASA Research Announcement (NRA) funded by NASA's Subsonic Fixed Wing Program (SFW). The project focuses on the design and wind tunnel test of a low-noise, cruise efficient, short take-off and landing (CESTOL) airliner that will improve prediction methods and technologies that can enable lower noise, emissions, and fuel burn ${ }^{2}$. Starting in 2007, California Polytechnic State University, San Luis Obispo, began the first of two phases of a 5-year NRA to develop a typical $\mathrm{N}+2$ airplane configuration that addresses the currently perceived needs of the civilian air transportation system. The second phase of the project focused on planning and executing a large-scale wind tunnel test using the configuration design from the first phase. The overall goal of the project is to generate validation data for Computational Fluid Dynamics (CFD) prediction tools that model aircraft with next generation capabilities. Developing a complete aircraft experimental database with the intent of validating predictive tools, able to predict the complex flow physics that an advanced transport presents, offers the unique prospect of reducing wind tunnel testing costs and the design cycle time of the next generation jet transport ${ }^{3}$. Cal Poly's design, AMELIA (Advanced Model for Extreme Lift and Improved Aeroacoustics), is seen in Fig. 1. This novel configuration utilizes circulation control wings (CCW) through leading- and trailing-edge blowing, as well as over-the-wing mounted engines. Technologies aimed at progress towards improved noise and field length performance are the focal point of the configuration. This paper focuses on the experimental efforts and resulting data generated from the wind tunnel test completed in February, 2012.

The use of circulation control (and other advanced flow control systems) coupled with advanced propulsion technologies can enable aircraft to exceed the take-off and landing goals and stringent noise regulations that accompany the escalating airport congestion, and meet the goals laid out by NASA's $\mathrm{N}+2$ generation. The current work focused on evaluating technologies, specifically those to improve noise and field length performance, with a technology readiness level of 4-6 with the aim of implementing an aircraft of similar design by 2020 (designated $\mathrm{N}+2$ ). The $\mathrm{N}+2$ goals are defined as a $25 \%$ reduction in

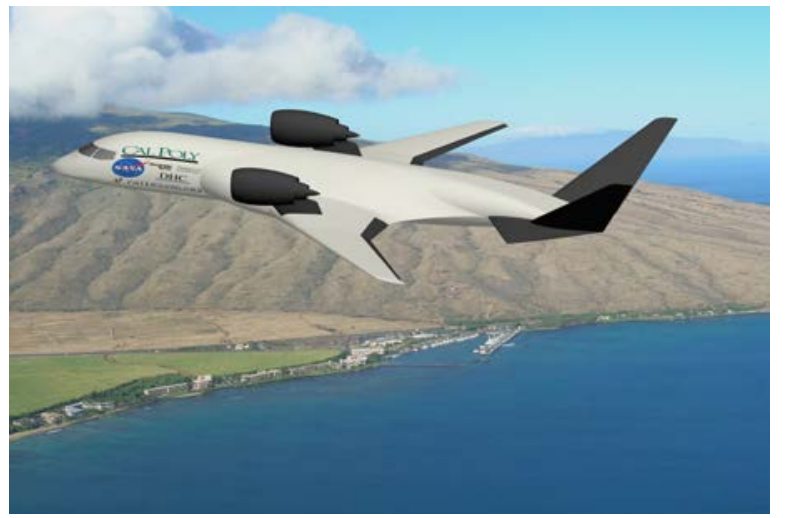

Figure 1. The Advanced Model for Extreme Lift and Improved Aeroacoustics. 
aircraft fuel burn, $-52 \mathrm{~dB}$ cumulative noise reduction below Federal Aviation Regulation 36 Stage 3, 80\% reduction in aircraft emissions, and a field length of less than 3000 feet.

The literature is well documented with publicly available research efforts focused on circulation control testing intended for CFD validation ${ }^{4-9}$. The majority of these tests, though, focus on 2-D, constant chord models with only trailing edge blowing. There is, however, significantly fewer efforts for 3-D tests with complete aircraft configurations. Collins ${ }^{10}$ and $\operatorname{Lin}^{11}$ completed a 3-D test of a full-span, hybrid wing STOL model with blown flaps. Most recently, Milholen ${ }^{12}$ documents the testing of a semi-span model with trailing edge blowing; the model is intended to test circulation control concepts at realistic flight Reynolds numbers for both low speed and transonic cruise conditions. Whereas the smaller scale tests are still relevant to the CFD community because many of the issues presented to the numerics are common between the 2-D and 3-D simulations (e.g., boundary layer separation, shear layers, and wake interactions), the present effort seeks to not only identify these complex flow physics, but also evaluate the highly coupled nature of these advanced flow control systems. This work seeks the fill the need for a complete aircraft configuration, open source, aerodynamic and acoustic data set intended for CFD validation.

\section{Experimental Set-Up}

\section{A. Test Facility - NFAC}

The wind tunnel test was conducted in the 40- by 80-foot test section at the National Full-Scale Aerodynamics Complex (NFAC) located at NASA Ames Research Center, Moffett Field, California. The NFAC is leased and operated by the Air Force's Arnold Engineering Development Center (AEDC). There are two test sections at the NFAC, comprising the largest wind tunnels in the world - the 40 - by 80 - foot and the 80 - by 120 -foot. The tunnels share a common fan drive, made up of six 40-foot diameter, 15-blade, variable-pitch fans, each powered by a 22,500 horsepower motor. An 8:1 contraction accelerates flow to a maximum test section velocity of 300 knots, or 0.45 Mach. The 40- by is a closed-circuit atmospheric wind tunnel with semi-circular walls, and a flat floor and ceiling. The test section walls are acoustically treated to permit aerodynamic and acoustic data to be acquired simultaneously. The acoustic treatment is composed of sound absorbing fiberglass wedges sunken in cavities below the liner, bringing the actual test section dimensions to 39 feet high by 79 feet wide (at the horizontal centerline). An aerial view of the NFAC is provided in Fig. $2^{\S}$.

The model utilized the NFAC's high pressure air (HPA) system. The facility system provided dry, heated air to AMELIA in two separate flow paths, each regulated by a 14-poppet Emco Digital Valve. The facility is capable of providing much greater flow capacity than what was required. The engine simulators were supplied air at up to $2 \mathrm{lb}_{\mathrm{m}} / \mathrm{sec}$ at $190 \mathrm{psig}$ and $110^{\circ} \mathrm{F}$. The slots were supplied up to 2.8 $\mathrm{lb}_{\mathrm{m}} / \mathrm{sec}$ at $210 \mathrm{psig}$ and $110^{\circ} \mathrm{F}$.

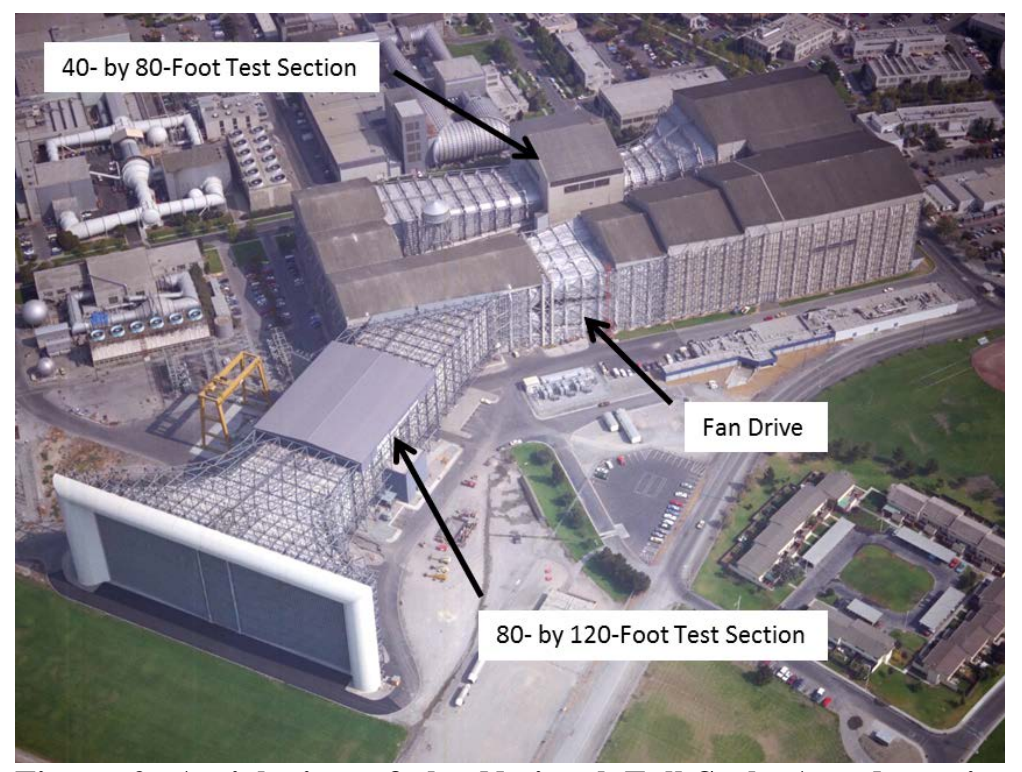

Figure 2. Aerial view of the National Full-Scale Aerodynamics Complex .

\section{B. Test Article - AMELIA}

The Advanced Model for Extreme Lift and Improved Aeroacoustics, shown in Fig. 3, served as the test article. AMELIA is a $1 / 11^{\text {th }}$ scale, 10 -foot, full-span model with leading- and trailing-edge blowing wing circulation control and over-the-wing mounted engine simulators. Here, circulation control is achieved by blowing a tangential jet onto a highly curved aerodynamic surface through slots at the leading- and trailing-edges of the wing. The outer mold lines of AMELIA form a hybrid blended wing body, whose design stems directly from NASA's N+2 generation goals. In the tunnel, the model is sting supported, sitting just over 2 feet above the test section centerline. Figure 4 shows the model mounted in the test section; the acoustic instruments can be seen in the figure as well. The engine

\footnotetext{
${ }_{\S}^{\S}$ Image courtesy of the National Full-Scale Aerodynamics Complex
} 
simulators sit atop removable pylons, enabling testing at 2 different engine heights. The model was manufactured to be modular. Although the empennage was manufactured, the model was tested with the tails removed. Patersonlabs, Inc. manufactured the model and applied the Imron coating, giving the model its black finish which is needed for the oil interferometry method. More information on the design of AMELIA can be found in Ref. 13.

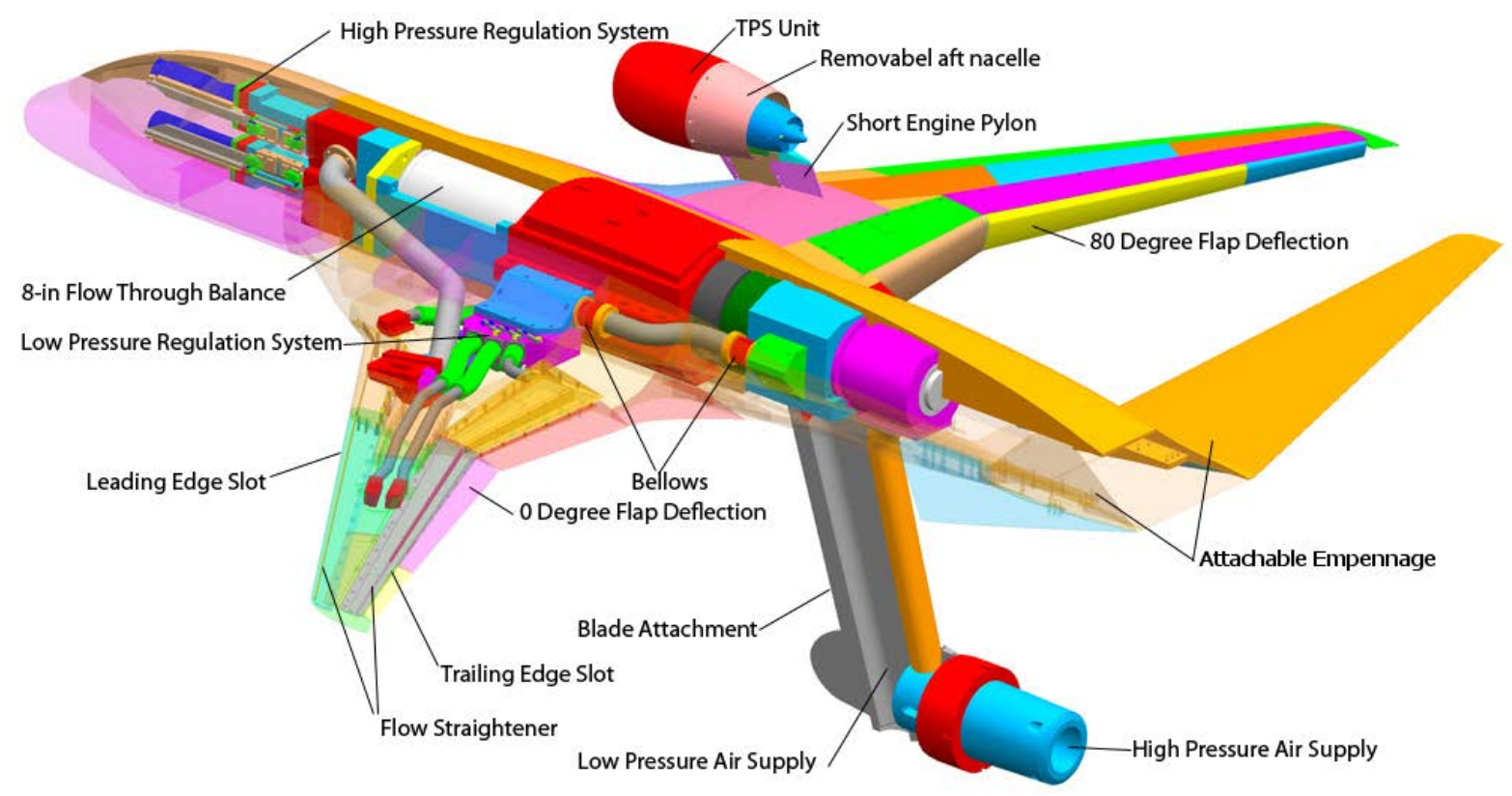

Figure 3. Internal layout of AMELIA.

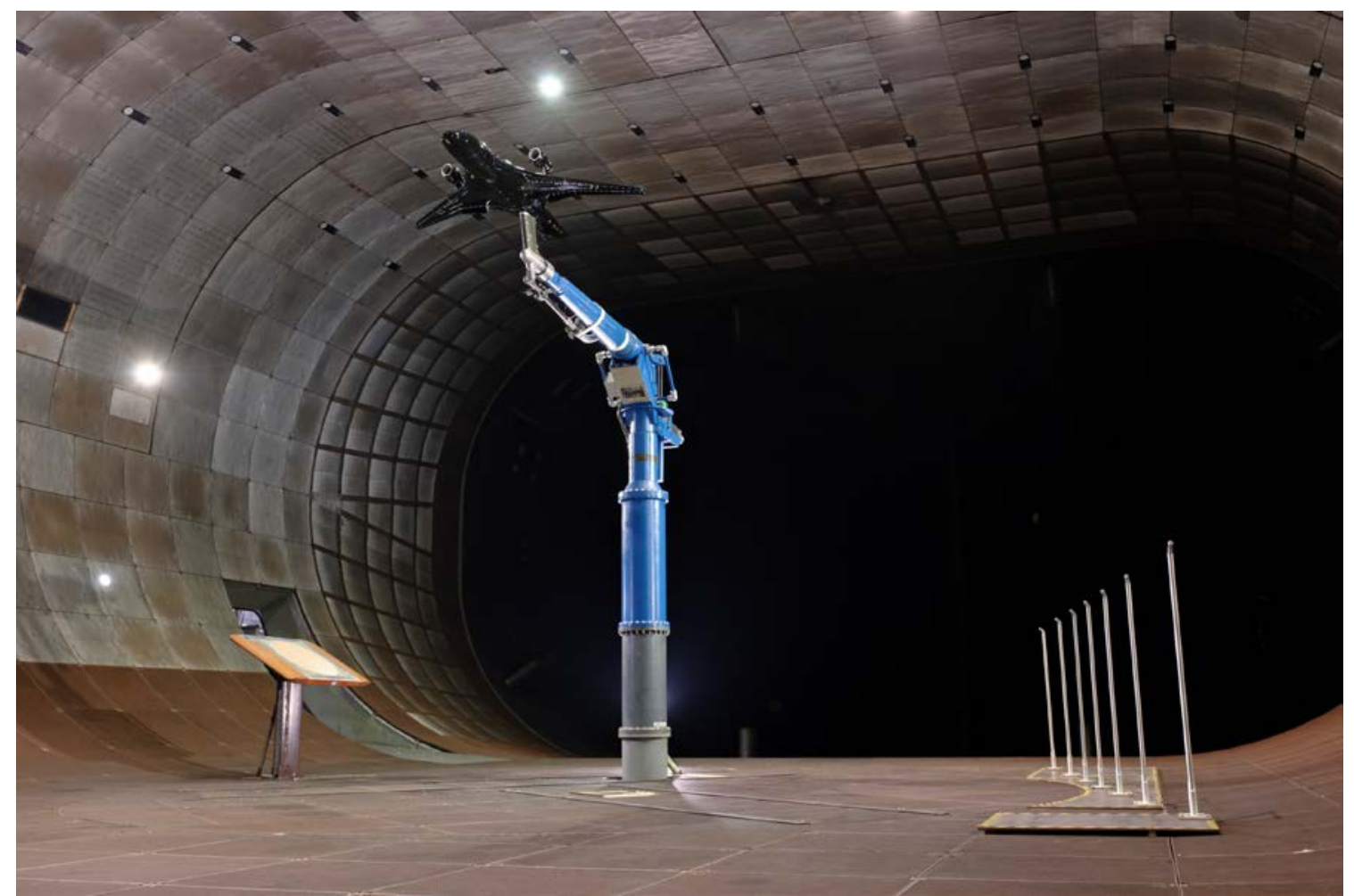

Figure 4. AMELIA mounted in the 40 - by 80 -foot test section at the NFAC. 
The wing section is a NASA supercritical airfoil, modified to accommodate the circulation control slots and dual-radius flaps. There are four removable dual-radius flaps, with deflections of $0^{\circ}, 30^{\circ}, 60^{\circ}$, and $80^{\circ}$. The wing has a reference area of $15.8 \mathrm{ft}^{2}$, an aspect ratio of 6.33 , a taper ratio of 0.174 , and there is no dihedral. The chord length at the start of the inboard slot is 32.7 inches and the mean aerodynamic chord is 22.4 inches.

The leading- and trailing-edge plenums have a contraction ratio of 15:1. The slot height to chord ratio is 0.00143 at the leading edge and 0.00238 at the trailing edge. The leading edge h/c holds until the local slot height reaches 0.012 inches, where it maintains this height until the end of the slot. A nominal cross-section view of the wing, with the $80^{\circ}$ flap deflection and plenum details highlighted, is shown in Fig. 5. As seen in the figure, the trailing edge slot height is set and secured using a push-pull system consisting of set-screws to hold the plenum under compression, and tie-downs to hold the slot height under pressurization. This system has seen past success in tests by Englar $^{14}$ and Cattafesta ${ }^{9}$. Static and pressurized measurements of the slot height were taken using a Capacitec Gapmaster3 and showed variations due to pressurization within the scatter of the uncertainty of the measurement. The leading edge slot does not have a similar push-pull system due to material thicknesses on the lower wing panel. As a result, the leading edge slot height is fixed once the panel has been fastened to the model. A description of the plenum flow straightening treatment and detailed slot height measurements are given by Paciano ${ }^{15}$.

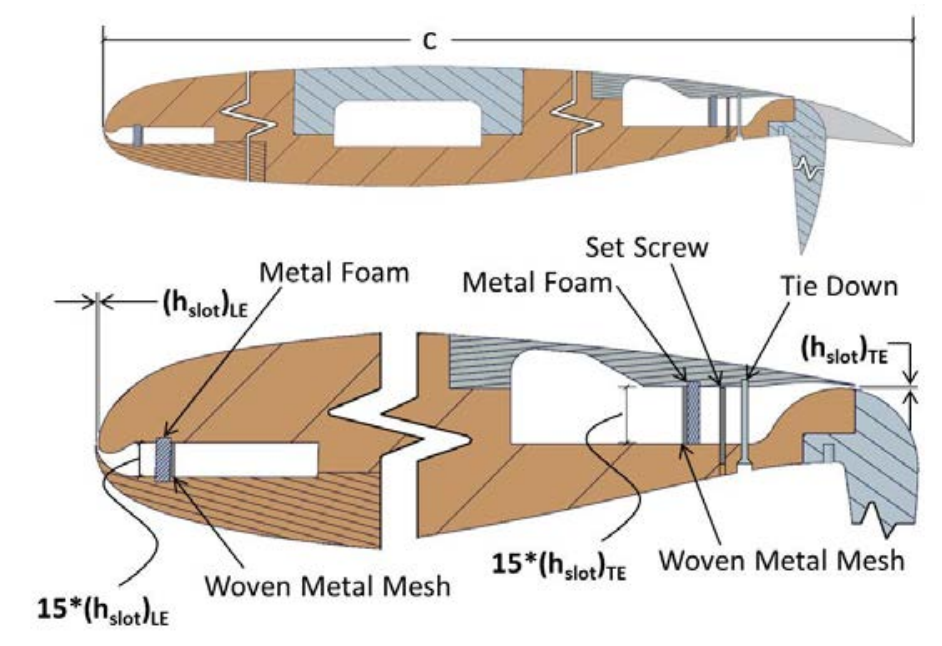

\author{
Figure 5. Nominal wing section and circulation control \\ plenum details.
}

\title{
C. Test Measurements and Instrumentation
}

Aerodynamic forces and moments were measured using the Triumph Force Measurement Systems MC-130 8.0 inch, flow-through balance. It is a 6-component balance with two internal air flow paths and one external flow path; forces are isolated on the external flow path through a system of bellows. The high pressure (TPS) side uses one of the internal flow paths, and the low pressure (slot blowing) side uses the external flow path.

Angle of attack was measured using redundant clinometers mounted in the nose of the model. An analog Q-Flex model QA-2000 temperature compensated accelerometer and a Schaevitz gravity referenced tilt sensor were used. Angle of attack measurements listed in this paper reference the Schaevitz sensor.

The model is instrumented with 232 static pressure ports. The ports are arranged in one spanwise group, and 5chordwise groups, located at semi-span locations of: $\eta=0.179,0.364$ (engine centerline), 0.758, 0.967, and 0.973. With the exception of 5 symmetric ports, the pressure taps are grouped on the left wing to keep the right wing clean for skin friction measurements. Model pressures were measured using the NFAC's PSI- Digital Temperature Compensated Initium system, with 2.5 psid and 15 psid electronically scanned pressure modules. There are 8 unsteady surface pressure transducers at locations near the TPS nacelle to measure engine noise and along the midfuselage at passenger level.

The engine simulators are Tech Development, Inc. (TDI) model 441 turbine propulsion simulators (TPS). Three TPS units were loaned to Cal Poly from NASA Langley Research Center. The units were refurbished by TDI and functionally calibrated by Georgia Tech Research Institute in 2011 prior to wind tunnel testing. The units are powered by high pressure air delivered through one of the internal balance flow paths. Two independently operated needle valves located in the nose of the model control air flow to each TPS. A thermocouple placed in the nose was used to monitor any excess temperatures that could cause thermal damage to pressure tubing and modules located in the vicinity of the TPS supply pipes. The units have a maximum rating of 45,000 RPM at $2.1 \mathrm{lb}_{\mathrm{m}} / \mathrm{sec}$ and $425 \mathrm{psig}$. Nominal test RPM was 77\% of max, or 34,500 RPM. The TPS are instrumented with forward and aft bearings (with thermocouples), and two RPM sensors. Core flow measurements were made with two each: total pressure probe, thermocouple, and static pressure port. The instrumentation is spaced radially around the core, $180^{\circ}$ from its respective duplicate. The nacelle inlet is instrumented with 8 , radially spaced, static pressure taps. The fan flow is 
instrumented with 7 radially spaced rakes. Each rake consists of 4 total pressure probes, 1 thermocouple, and a static pressure tap at the base of the rake. TPS vibrations were monitored using one three-axis accelerometer per unit.

At the base of the model/blade interface, the low pressure line splits into two sides for the left and right wings. Two low pressure manifolds serve as the distribution point for each wing. Each low pressure manifold controls air flow to the plenums located on each wing through 4 independently operated butterfly valves. The manifold, or distribution plenum, is instrumented with an unsteady pressure transducer and a thermocouple. The left and right side thermocouple measurements are averaged to provide the temperature used in the calculation of the momentum coefficient (see Summary of Test Conditions located in section IV for the calculation of momentum coefficient). Each of the 8 plenums is instrumented with three total pressure probes, located at the middle and outside edges of the plenum. The plenums are designated: LEIB (Leading Edge Inboard), LEOB (Leading Edge Outboard), TEIB (Trailing Edge Inboard), and TEOB (Trailing Edge Outboard). Mass flow rate for the slot blowing side was measured using an orifice plate. The orifice plate was calibrated post-test and data presented herein reflect incorporation of the calibration data. The orifice plate was mounted externally on the sting assembly, just upstream of the blade attachment.

In addition to the measurements listed above, direct measurement of skin friction using the Fringe Imaging Skin Friction (FISF) technique was obtained during each of the ten critical test points. The FISF technique is a nonintrusive method for the measurement of global skin friction direction and magnitude ${ }^{16}$. Twelve surface mounted thermocouples on the right wing are used for the determination of the correct oil viscosity. The temperatures are acquired on the NFAC LXI system.

\section{Data Acquisition}

Data were acquired on four different data systems in place at the NFAC; a more complete description of the NFAC DAS is given by van Aken ${ }^{17}$. Model pressures on the PSI-Initium system, thermocouples, and tunnel wall pressures totaling 365 channels were acquired at $10 \mathrm{~Hz}$ on the steady data acquisition system (SDAS). 143 channels including the high pressure air system were acquired at $1 \mathrm{kHz}$ on the $\mathrm{N} / \mathrm{rev}$-pulse based, basic DAS (BDAS). Wind tunnel and model health were monitored on 96 safety-of-flight channels acquired at $1 \mathrm{kHz}$ (SOFDAS). Wind-on data points were acquired for 32 seconds, and wind-off data points for 4 seconds. Data point duration was determined from the results of a data point duration study, not presented here. Acoustic measurements are acquired on a separate data system, see Burnside ${ }^{18}$ for details.

In addition to the data acquired from model and tunnel sensors, content from $4 \mathrm{HD}$ cameras mounted in the test section was recorded. The video feed was used for flow visualization during both the smoke and oil runs. Videos are made available along with the data sets.

\section{E. Summary of Test Conditions}

Testing was conducted at three velocities: $40 \mathrm{KTS}, 60 \mathrm{KTS}$, and $100 \mathrm{KTS}$. Table 1 provides test average and variances on the velocity dependent parameters: dynamic pressure, Mach number, and Reynolds number based on mean aerodynamic chord. Set-point tolerance on velocity was $\pm 0.1 \mathrm{KTS}$, and $\pm 0.1^{\circ}$ on angle of attack. Deviation in the remaining column values is primarily due to variation in tunnel atmosphere; intervals are presented with $95 \%$ confidence.

Table 1. Summary of wind tunnel flow conditions.

\begin{tabular}{|c|c|c|c|}
\hline Tunnel Velocity, KTS & $\mathrm{M}$ & $\mathrm{q}_{\infty}, \mathrm{psf}$ & $\mathrm{Re}_{\mathrm{c}}, 10^{6}$ \\
\hline $40 \pm 0.1$ & $0.061 \pm 0.001$ & $5.5 \pm 0.2$ & $0.82 \pm 0.05$ \\
\hline $60 \pm 0.1$ & $0.091 \pm 0.004$ & $12.4 \pm 0.3$ & $1.23 \pm 0.23$ \\
\hline $100 \pm 0.1$ & $0.151 \pm 0.002$ & $33.5 \pm 0.5$ & $1.99 \pm 0.05$ \\
\hline
\end{tabular}

Data acquired during an alpha sweep were generally obtained over a range from $-5^{\circ}$ to $+25^{\circ}$. Runs at high speed and high blowing conditions that saw considerable model vibrations were held to a smaller positive alpha limit; this angle of attack limit was subjective and dependent on the magnitude of the vibrations. During an alpha polar, the model is held at a single slot and TPS power setting and swept through the angle of attack range. Slot sweep data were acquired at a fixed angle of attack over a mass flow rate range from $0 \mathrm{lb}_{\mathrm{m}} / \mathrm{sec}$ to $2.8 \mathrm{lb}_{\mathrm{m}} / \mathrm{sec}$. The upper limit is $1.55 \mathrm{lb}_{\mathrm{m}} / \mathrm{sec}$ for the trailing edge-only blowing configuration. The above mass flow numbers reference the digital valve set-point; the digital valve is the reference to set on-condition for both the TPS and slots (there is 1 digital valve per line). Note that this reference is not the true value per se, but it serves as a nominal value used for reference. Mass flow rate numbers listed elsewhere (e.g. those used in the calculation of $C_{\mu}$ ) are from the calibrated orifice plate and represent the true value. 
Table 2 presents individual plenum nozzle pressure ratio (NPR) and total summed average NPR as a function of the slot blowing configuration and set-point. Individual plenum NPRs are the average of the three internal total pressure probes. The values listed in the table represent test-wide averages for the specified set-point; though, runto-run NPR will vary by a few percent due, primarily, to time-of-day and tunnel atmosphere. The NPR calculation uses the freestream static pressure, instead of the jet exit. Although using the jet exit would yield a higher value and truer estimate of the actual NPR, using the freestream pressure allows for meaningful comparison between data at different test conditions. Individual figures are labeled with the average momentum and thrust coefficient as these values are more directly dependent on dynamic pressure.

Table 2. Individual plenum and average nozzle pressure ratio summary.

\begin{tabular}{|c|c|c|c|c|}
\hline Blowing configuration & $\begin{array}{l}\text { Total } \dot{m}^{\mp} \\
\mathrm{lb}_{\mathrm{m}} / \mathrm{sec}\end{array}$ & Average NPR & Plenum & $\mathrm{NPR},\left[\left(P_{0}\right)_{\text {plenum }} / P_{\infty}\right]$ \\
\hline \multirow{8}{*}{$\begin{array}{l}\text { Combined LE- and TE-blowing } \\
\text { (Runs 18-270) }\end{array}$} & \multirow{4}{*}{2.80 (full) } & \multirow{4}{*}{1.50} & LEIB & 1.63 \\
\hline & & & LEOB & 1.36 \\
\hline & & & TEIB & 1.67 \\
\hline & & & TEOB & 1.35 \\
\hline & \multirow{4}{*}{$1.87(2 / 3)$} & \multirow{4}{*}{1.22} & LEIB & 1.27 \\
\hline & & & LEOB & 1.14 \\
\hline & & & TEIB & 1.30 \\
\hline & & & TEOB & 1.15 \\
\hline \multirow{4}{*}{$\begin{array}{l}\text { TE-only blowing } \\
\text { (Runs 271-312) }\end{array}$} & \multirow{2}{*}{1.55 (full) } & \multirow{2}{*}{1.57} & TEIB & 1.74 \\
\hline & & & TEOB & 1.39 \\
\hline & \multirow{2}{*}{$1.03(2 / 3)$} & \multirow{2}{*}{1.26} & TEIB & 1.34 \\
\hline & & & TEOB & 1.17 \\
\hline
\end{tabular}

Total mass flow rate references the digital valve set-point

Table 3 presents TPS operating conditions at the nominal set-point. The values listed in the table represent testwide averages with variances given at 95\% confidence levels. The fan and core nozzle pressure ratio, FNPR and CNPR, is calculated by dividing the average of the total pressure probes in the respective stream by the freestream static pressure.

Table 3. Nominal TPS set-point operating conditions.

\begin{tabular}{|c|c|c|c|c|c|}
\hline $\mathrm{RPM}$ & $\dot{m}, \mathrm{lb}_{\mathrm{m}} / \mathrm{sec}$ & $P_{\text {line }}, \mathrm{psig}$ & Thrust $^{\ddagger}, \mathrm{lb}_{\mathrm{f}}$ & FNPR & CNPR \\
\hline $34,342 \pm 328$ & $1.95 \pm 0.03$ & $195 \pm 8$ & $187.6 \pm 4.4$ & $1.33 \pm 0.01$ & $1.12 \pm 0.01$ \\
\hline
\end{tabular}

The thrust coefficient, $C_{T}$, is calculated based on the combined gross thrust of the TPS.

$$
C_{T} \equiv \frac{\text { Thrust }}{q_{\infty} S_{\text {ref }}}
$$

Thrust is calculated based on a look up table from a calibration.

The momentum coefficient, $C_{\mu}$, characterizes the performance of a circulation control wing. It is also referred to as the blowing coefficient, discharge coefficient, or jet momentum coefficient. It is defined in the same way as the thrust coefficient.

$$
C_{\mu} \equiv \frac{\text { Thrust }}{q_{\infty} S_{\text {ref }}}=\frac{\int\left(\rho_{j} \overrightarrow{V_{J}} \cdot \vec{n}\right)\left(\overrightarrow{V_{j}} \cdot \vec{n}\right) d A}{q_{\infty} S_{\text {ref }}}
$$

The subscript $j$ denotes properties with respect to the jet flow (i.e. in the slot). The integral in the numerator of Eq. (2) is approximated as

$$
C_{\mu}=\frac{\dot{m}_{j} u_{j}}{q_{\infty} S_{r e f}}
$$


The small slot height makes direct measurement of the jet velocity difficult, so it is standard to approximate using isentropic relations. For isentropic flow, the jet velocity is

$$
u_{j}=\left[\frac{2}{\gamma-1} \gamma R T_{t, j}\left(1-\left(\frac{P_{j}}{P_{t, j}}\right)^{\frac{\gamma-1}{\gamma}}\right)\right]^{1 / 2}
$$

The specific heat ratio, $\gamma$, is 1.4 , and the gas constant, $R$, for dry air is $1716.59 \mathrm{ft}-\mathrm{lb}_{\mathrm{f}} / \mathrm{slug}-\mathrm{R}$. It is also common practice to substitute the freestream static pressure in lieu of the jet static pressure, $P_{j}$. From a technical standpoint, this will yield a lower jet velocity than actual, and for CFD, should be calculated from expansion to the local static pressure using, say, the static pressure taps located at the leading edge and on the flaps. The reason $C_{\mu}$ is reported using expansion to the freestream static pressure is because the local static pressure will change with angle of attack or any geometry change in the CCW surface (i.e. flap deflection), thus making comparison between model configurations and alpha sweeps not meaningful. As measuring the mass flow rate into each of the 8 individual plenums was not possible, the reflected $C_{\mu}$ is a combined momentum coefficient for the system. i.e. The total pressure term in Eq. (4) is the average of all 24 plenum total pressure measurements.

\section{Model Configurations}

The results that follow will be discussed based on the four basic model configurations; they are: low engine pylon height, high engine pylon height, clean wing - leading- and trailing-edge blowing, and clean wing - trailing edge-only blowing. The low and high pylon heights were both tested with leading- and trailing-edge blowing, but they will be referred to by their pylon heights, henceforth. The clean-wing combined leading- and trailing-edge blowing will be referred to as the clean wing configuration, while the clean wing trailing edge-only blowing will be referred to as the trailing edge-only, or TE-only configuration. This section gives a brief introduction to each configuration including important data trends.

\section{A. Clean Wing}

Originally, testing was only planned for the low- and high-pylon heights. Low priority runs were sacrificed late in the test planning phase to add the clean wing runs. This decision was justified because of the value the clean wing runs present to the CFD community. The removal of the TPS units provides a much simpler validation case for CFD; it is likely that a CFD validation will start with this configuration (or the TE-only blowing configuration) before attempting a simulation with the entire model. The addition of the TPS, and the coupling of the CCW and over-the-wing mounted engines, significantly complicates the flow physics. The TPS also add a significant burden to building the computational grid and implementing boundary conditions.

A Bondo product was used to fill the hole in the wing in the absence of the TPS unit. The Bondo was formed to match the wing mold lines and a FARO measuring arm was used to acquire geometric points, post-test, to confirm the mold lines of the wing in relation to the manufactured CAD model. Testing in the clean wing configuration took place over 5 wind-on days, wherein 64 useful data runs and one critical test point were acquired. Data presented in this configuration has leading- and trailing-edge blowing.

\section{B. Trailing Edge-Only Blowing}

The isolated trailing edge blowing configuration runs were conducted over the final two days of wind-on testing. As a result, only a limited subset of data at the $0^{\circ}$ and $60^{\circ}$ flap deflections are available. In this configuration, the leading-edge plenums have been blocked at the downstream side of the butterfly valves and the TPS have been removed (hence the clean wing). To set on-condition for this configuration, the trailing-edge plenum pressures were matched to what was set for the combined leading- and trailing-edge blowing runs. The result is slightly more than half the mass flow rate, as the split between the leading- and trailing-edges is not exactly half of the total air delivered to the low pressure side of the model. See Table 2 for details.

As was discussed in the introduction, the majority of circulation control testing focuses on models that are limited to trailing edge blowing. As this wind tunnel test was a first on many fronts, it was important to have a subset of data available to compare against historical data. Results from these experiments have shown large lift augmentation through TE-blowing can be achieved, however performance falls off at positive angles of attack - stall at the leading edge is the cause. Circulation control can be thought of as effective camber; as blowing coefficient is increased, the more effective camber the wing has. At high blowing rates the effect is manifested at the leading edge, where the stagnation point moves further downstream on the lower surface to a point where it cannot maintain 
attachment through the increased acceleration around the nose. Previously, a leading-edge device (such as a slat) has been employed in an attempt to delay stall at the leading edge. Although effective at delaying stall to higher angles of attack, the leading-edge article is not entirely sufficient and leading-edge blowing is necessary. The reader is encouraged to refer to these papers by Englar ${ }^{5,6}$ for more information on prior circulation control testing.

Figure 6 shows a typical lift curve for AMELIA for trailing edge-only blowing at $40 \mathrm{KTS}$ and $60^{\circ}$ flap deflection. The figure shows that although blowing greatly augments the lift generation, the locus of stall points moves below $\alpha=12^{\circ}$ as $C_{\mu}$ is increased. At $C_{\mu}=0.38$, the model stalls at $0^{\circ}$ angle of attack - the need for leadingedge blowing is evident.

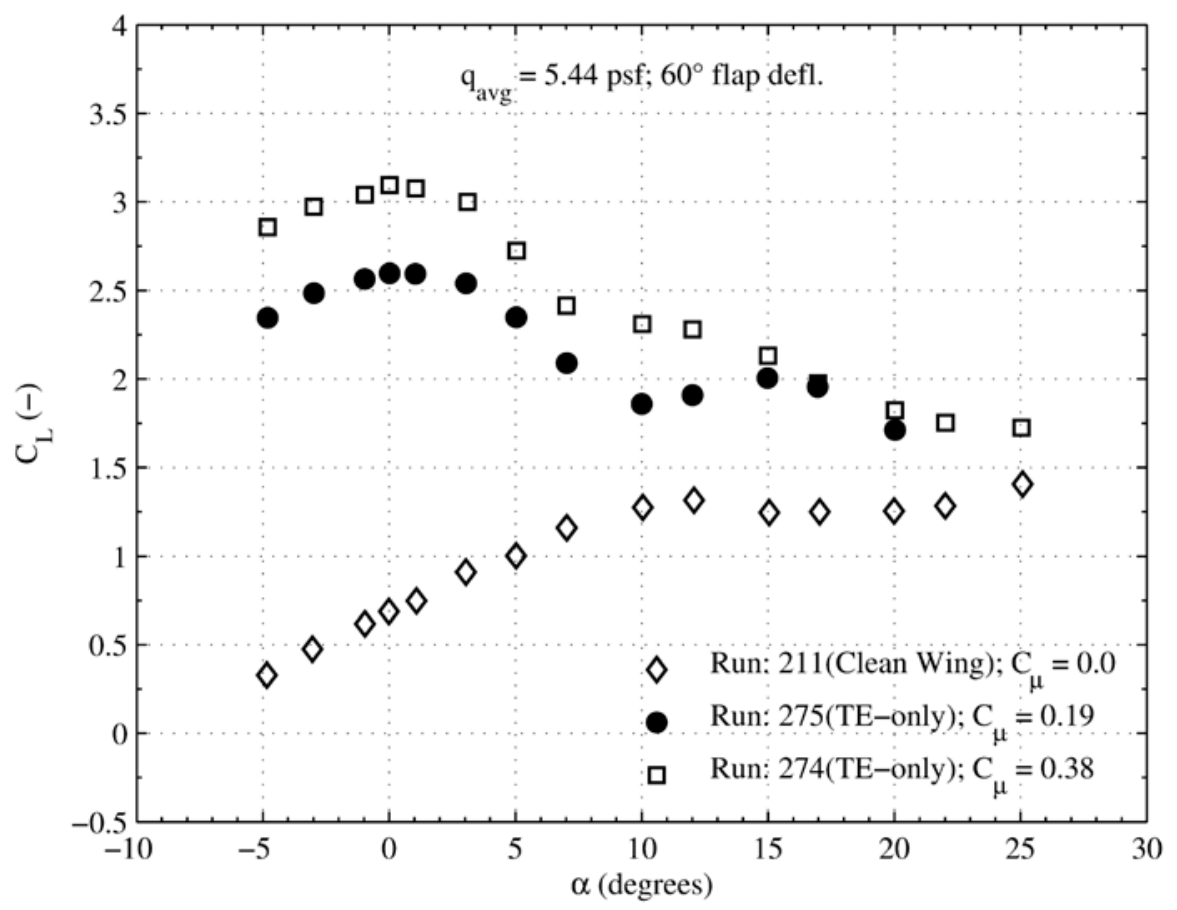

Figure 6. Typical lift curve for TE-only blowing configuration. $q_{\infty}=5.4 \mathrm{psf}, 60^{\circ}$ flap deflection.

\section{Low Pylon Height}

The low engine pylon height was the first configuration tested. Testing in this configuration lasted for a period of 20 wind-on days, wherein 151 useful data runs were acquired. Six critical test points, five oil flow visualization, and two smoke flow visualization runs were also completed in this time. The results from the oil flow and smoke flow runs are not presented here, but are available with the wind tunnel data sets. For safety, the TPS were not in operation during the smoke flow runs.

The data are left uncorrected, so the thrust component from the TPS is present in the data. The addition of the engine thrust increases the lift curve slope because it includes the thrust coefficient component, to be discussed in the next section. Because the aerodynamic data are presented in the wind axis-system and drag is aligned parallel to the local freestream, the majority of the thrust component from the TPS units is present in the drag axis and results in a negative value (often referred to as thrust recovery). It will be emphasized later, but the increase in lift when the engine simulators are on is not so much due to the thrust deflection angle, but more due to the increased wing upper surface velocities and resulting decreased static pressures. In general though, larger lift augmentation is achieved from increasing $C_{\mu}$ rather than increasing $C_{T}$. The data will show that even at high angles of attack, the addition of leading-edge blowing alone is not enough to prevent wing stall.

\section{High Pylon Height}

The model change from the low pylon to the high pylon height took place over a day with minimal loss of instrumentation and testing was able to proceed with no down-time incurred. Testing at the two pylon heights 
allowed for the highly coupled CCW and over-the-wing mounted design to be characterized, both aerodynamically and acoustically.

The high pylon height measures 6.26 inches from the wing upper surface to the TPS centerline; the low pylon measures 4.21 inches along the same reference. Non-dimensionalizing by the fan diameter $(D)$ of 5 inches, the high and low pylon heights correspond to a $z / D$ of 1.25 and 0.84 fan diameters above the wing upper surface, respectively. Figure 7 shows a close-up front view of the wing/engine configurations.

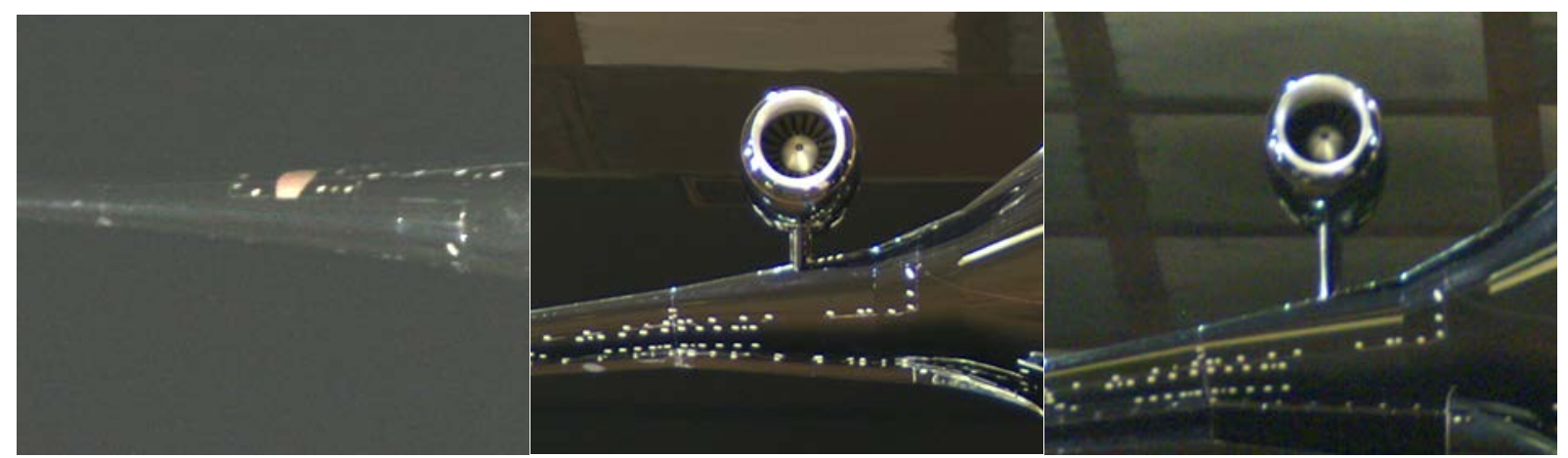

Figure 7. Front view of the engine configurations. Left to right: clean wing, low pylon height, and high pylon height.

\section{Experimental Results and Analysis}

This section presents a summary of basic model aerodynamic performance results obtained during the AMELIA wind tunnel test, completed in February, 2012. Before the results are discussed, some general comments on the wind tunnel test are in order. The model performed extremely well throughout the test. All test objectives, including ten critical test points, were successfully completed. Direct measurement of skin friction using the FISF (Fringe Imaging Skin Friction) method was employed for each critical test point. Six different surface oil-flow visualization and two smoke-wand visualization runs were completed. The test matrix incorporated sets of repeat runs at different model configurations and tunnel conditions. The test provided low-speed experimental force and moment data for the $\mathrm{N}+2$ AMELIA model, including surface pressure and acoustic measurements. This is the first wind tunnel test of a fullspan model incorporating leading- and trailing-edge blowing wing circulation control and engine simulators. It is also the first comparison of trailing edge-only blowing aircraft performance versus leading- and trailing-edge blowing aircraft performance. The objective is to utilize the test data to improve CFD tools for modeling $\mathrm{N}+2$ configurations.

All data presented herein is with respect to the wind axis-system, as defined by the AIAA guide ${ }^{19}$. The data presented are not corrected for wind tunnel wall or model support interference effects. As the data sets are intended for CFD validation, corrections to free-air conditions are not necessary. Wall pressure data was recorded, but is not presented. Flow angularity in the test section is not known and no data corrections have been applied; the most recent flow characterization was completed in $1989^{20}$. Weight tares for each model configuration have been applied to the data sets. No additional corrections have been made to the data sets to account for either the thrust effects from the TPS units or the pressure tares for the circulation control wings. It is common place to correct for the propulsive effects of the TPS units, i.e. subtract the components of the thrust vector that are parallel and perpendicular to the freestream vector from lift and drag. While this may be correct for pure jet flaps, where the true thrust value and its direction are known (or can be determined), it is not the case for powered-lift or a CCW-based powered-lift system like AMELIA. In a powered-lift flow field, the thrust value and direction changes with dynamic pressure, momentum coefficient, and local slot height. Subtracting the thrust coefficient component, $C_{T}{ }^{*} \sin \left(\alpha+\delta_{j e t}\right)$ [from the lift coefficient], does not accurately account for the complex flow-field. Therefore, the data sets are left as total measured forces and coefficients. However, should it be determined that the thrust coefficient component is sufficient, wind-off TPS-on alpha sweeps can be used in an attempt to correct the data sets. Static alpha sweeps were also conducted for slot blowing-only, if any attempt at correcting slot pressure tares be made.

Boundary layer transition was fixed using trip dots placed discretely on the model. The dots were sized to create fully turbulent flow over the entire model when the slots are not blowing. When the slots are blowing, the dots are enough to trip the flow if it is not already contaminated from the leading edge plenums. The trip dots were sized following a routine derived from Braslow ${ }^{21}$, and were placed at $12 \%$ of the local chord. Using the fact that there is higher shear in a turbulent boundary layer, as compared to a laminar boundary layer, oil fringes were used to 
visually verify transition at the nose and over the wing upper surface. More shearing creates a thinner oil film layer and thus larger fringe spacing. Photographs from the FISF database can verify this assessment, but none are presented here.

\section{A. Data Repeatability}

Estimation of the repeatability (or precision) error for the AMELIA test data follows. Precision error is the random component of the total error that has to do with the difference between a measured value and the population mean of measured values (i.e. the data scatter). Because precision error is the random component of the true error, statistical analysis is used to estimate the data mean and express the data scatter about the estimated mean with a specified level of confidence. The method of analysis employed here is referred to as multivariable regression statistical analysis; the method is used by Wahls ${ }^{22}$ and is consistent with the AIAA standard ${ }^{23}$. In this method, the data sample mean is estimated by a single least-squares curve fit based on all data from a set of identical runs. It is assumed that the data scatter is random and can be represented by a normal distribution, and that the dependent variable can be represented as a single function of the independent variable using a polynomial regression equation. For this analysis, the independent variable is angle of attack. The dependent variables presented here are $C_{L}, C_{D}$, and $C_{m}$. The data scatter about the mean is quantified with confidence and prediction intervals on the bounds. The confidence interval is defined as the bounds about which the estimated mean encompasses the true mean, and the prediction interval is defined as the bounds about which the estimated mean will contain any single future observation. The bound widths are equivalent to the level of confidence in the statistical analysis; here 95\% confidence and prediction levels are reported.

The results of the repeatability analysis are presented below in Figs. 8-13. Out of a total of 292 data runs, fourteen different repeat run configurations were obtained. For the sake of brevity, only one set of figures is provided at each time scale. The time scales are defined in a following paragraph. The regression analyses were based on data acquired over the entire angle of attack range within a given set of repeat runs. Each figure presents the original polar and the residuals from each curve fit. The residuals, or delta coefficients, are defined as the difference between the least-squares estimation of the data sample mean and the measured value at a given angle of attack.

$$
\Delta Y=Y_{i}-\hat{Y}_{i}
$$

The statistical quantities listed in the lower subplot of each figure provide a summary of relevant statistics for each regression. The quantities represented are: the order of the least-squares curve fit, $K$, the goodness of fit, $R^{2}$ (coefficient of determination), and the standard error, S.E., for each regression. It should be noted that this analysis accounts for the data density such that more populated regions have narrower confidence and prediction intervals than those that are sparser. This effect can be seen in the widening of both prediction and confidence intervals at the ends of the data range, where the mean value is known with less confidence because the data are less concentrated in these regions.

Though there were no pre-test goals set, overall repeatability for coefficients of lift, drag, and pitching moment are good. As is intuitive, the un-powered runs have better repeatability than the powered runs. Repeatability is generally better for more closely space runs and is sensitive to the time of day; two primary reasons contribute to this: the tunnel is un-pressurized and the HPA temperature shifts throughout the day as it is heated. There are a large number of possible sources of error that may contribute to non-repeatability in test data. Several likely sources include (but are not limited to): balance accuracy, balance temperature effects, angle of attack measurement, repeatability of wind tunnel flow conditions, and HPA properties. All of the aforementioned sources have been quantified and listed elsewhere ${ }^{24}$. Issues with pressure tubes and other cables bridging the metric and non-metric sides of the balance causing fouling to occur have not been quantified but are not expected.

There are three time scales within which the data repeatability is classified - short term, near term, and long term. These time scales refer to the elapsed time in between repeated runs and the number of model changes (a flap change is considered a model change), if any, between repeated runs. As this model has only had one tunnel entry to date, the time scales are defined different than what is in the literature. Here, short-term time scale is based on runto-run repeatability with no model changes, i.e. repeat runs either back-to-back or within the same day. Near-term time scale is based on day-to-day repeatability with no model changes, i.e. runs separated by at least a day with no flap changes in between. Long-term time scale is based on week-to-week repeatability with multiple model changes in between. Table 4 summarizes the repeatability over the three time scales, separated by powered and un-powered runs. A powered run is considered one where the TPS and/or the slots are blowing. The values presented are simply 
the averages of the $95 \%$ confidence intervals for all runs in the indicated time scale. The statistics from the back-toback runs are listed in a separate column, but are included as a part of the short-term averages listed.

Table 4. Average $95 \%$ confidence repeatability as a function of powered and un-powered runs, and time scale.

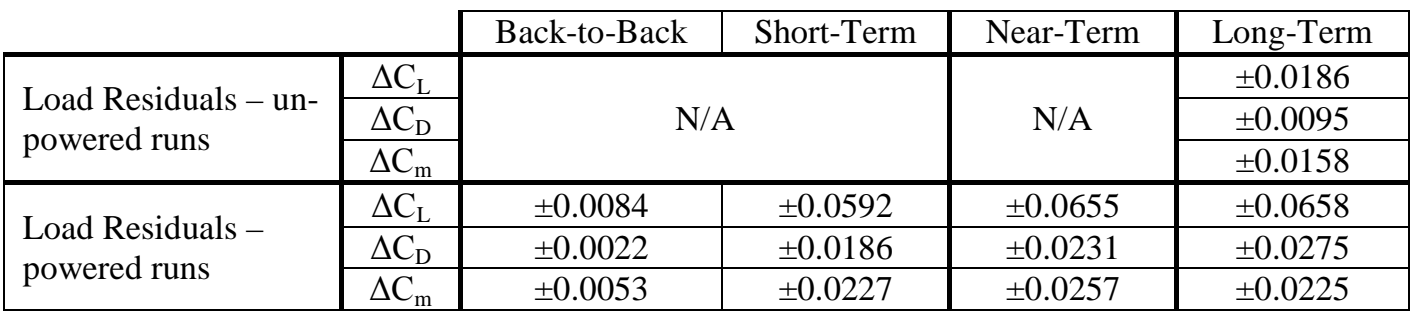

Repeatability for model pressures was also analyzed. For 95\% confidence, the model pressures are repeatable to \pm 0.045 psia on the 15 psid modules and \pm 0.035 psia on the 2.5 psid modules. It is expected that the uncertainty in the lower range PSI modules is smaller. Repeatability in $C_{P}$ measurements is \pm 0.335 for 15 psid modules and \pm 0.049 for 2.5 psid modules. Individual plenum pressures are slightly less repeatable than the overall model pressure confidence levels. This is to be expected as the plenum pressures are sensitive to parameters like line temperature and nozzle exit pressure.
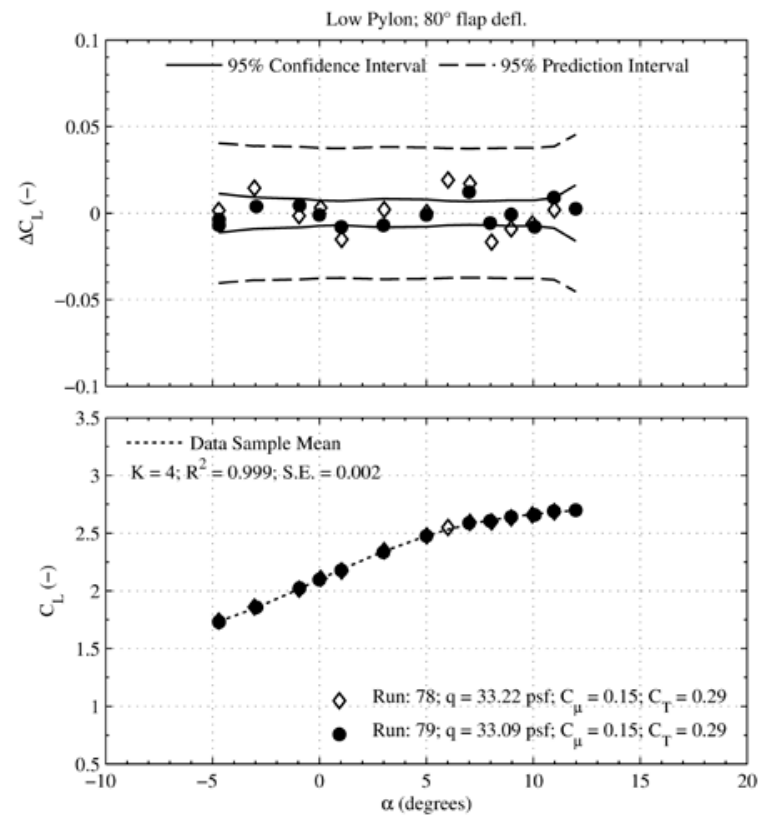

Figure 8. Short-term lift coefficient repeatability. $q_{\infty}=33 p s f$.
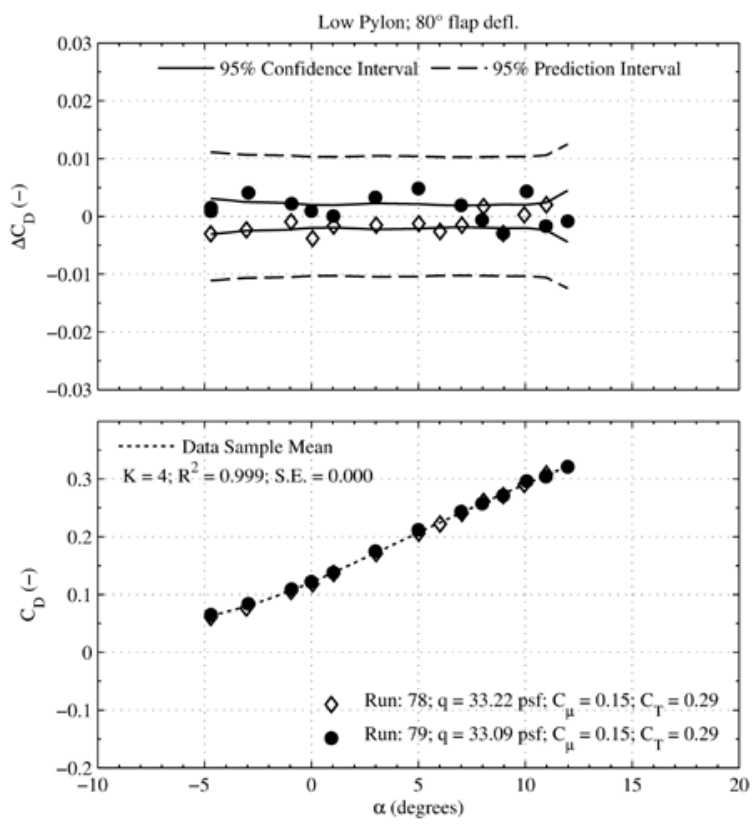

Figure 9. Short-term drag coefficient repeatability. $q_{\infty}=33 p s f$. 


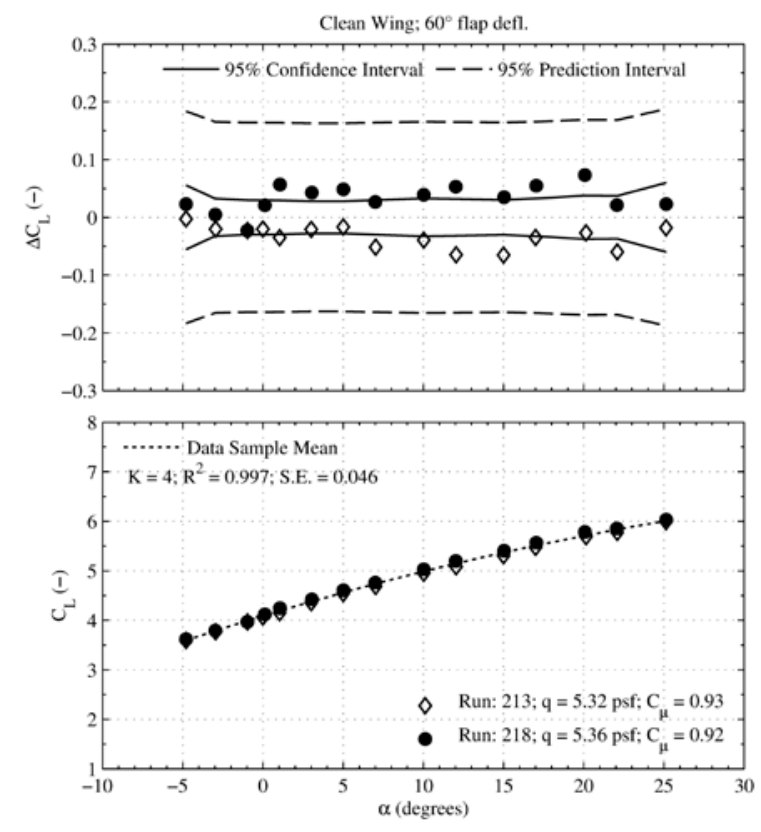

Figure 10. Near-term lift coefficient repeatability. $q_{\infty}=5.3 \mathrm{psf}$.

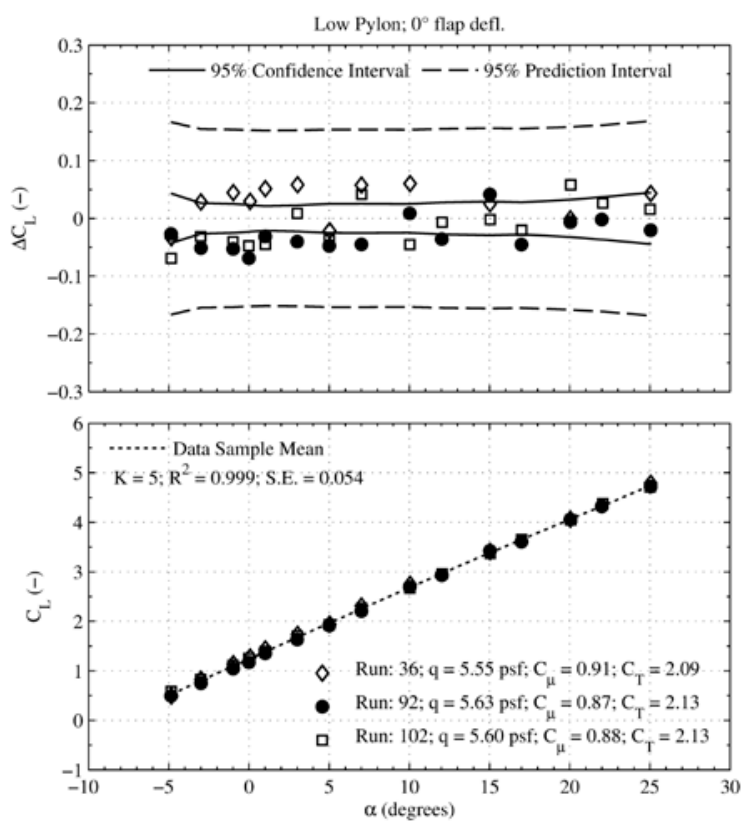

Figure 12. Long-term lift coefficient repeatability. $q_{\infty}=5.6 \mathrm{psf}$.

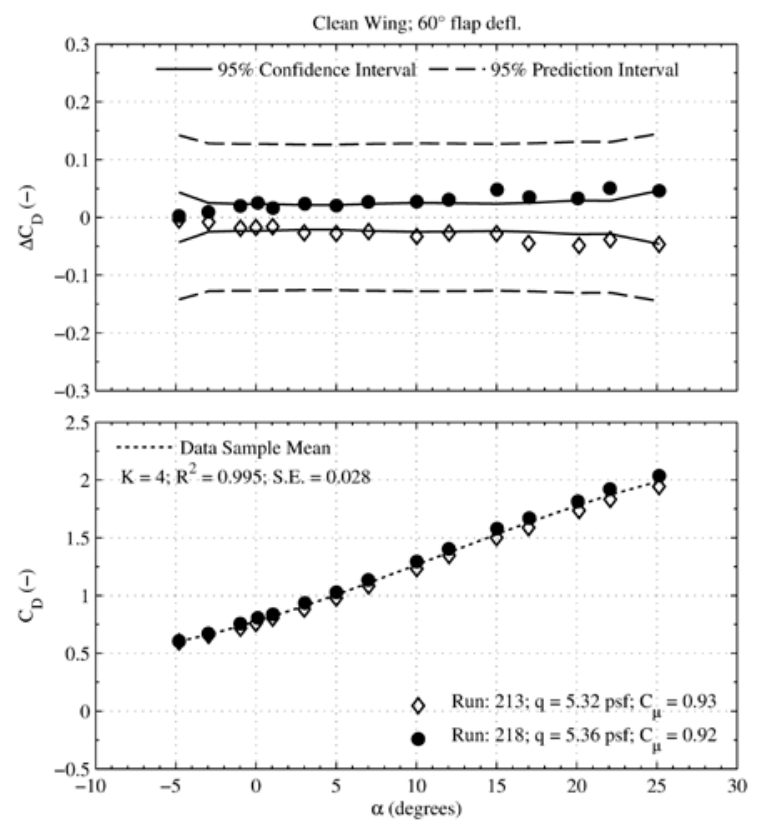

Figure 11. Near-term drag coefficient repeatability. $q_{\infty}=5.3 \mathrm{psf}$.

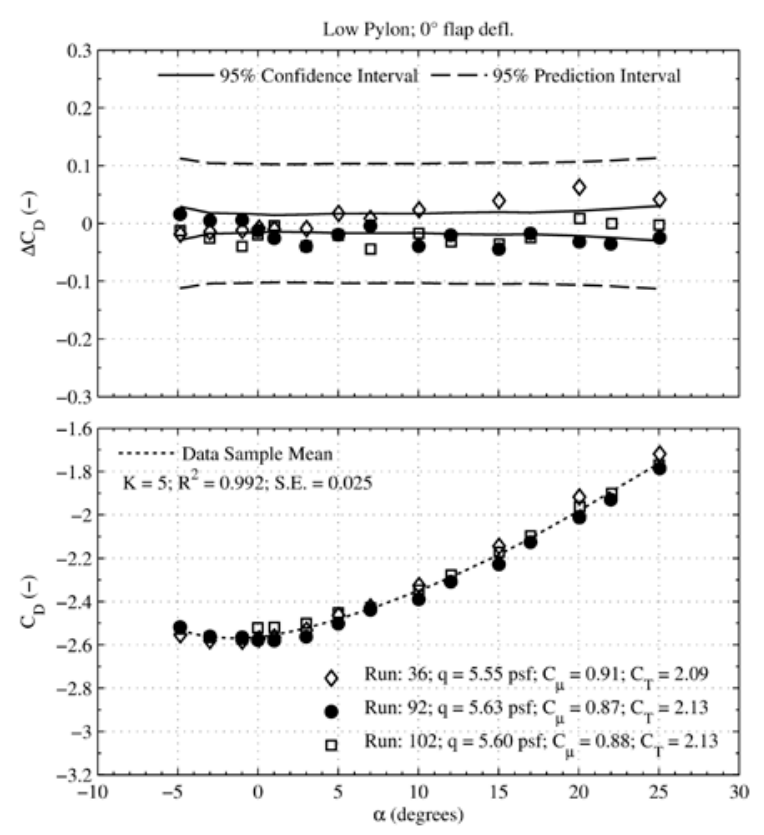

Figure 13. Long-term drag coefficient repeatability. $q_{\infty}=5.6 \mathrm{psf}$. 


\section{B. Aerodynamic Performance Results}

Momentum coefficient sweep data are presented in Fig. 14 for a fixed flap deflection and tunnel speed. In the figure, $C_{L}$ increases with angle of attack across the slot sweep range. There is a noticeable drop-off in $C_{\mathrm{L}}$ with increasing $C_{\mu}$ at $\alpha=10^{\circ}$, though. Here, the wing has stalled at the leading edge and becomes ineffective at generating lift through increased circulation from blowing. Reference Fig. 6 for the lift curve at this condition. The region at low $C_{\mu}$ where the increase in $C_{L}$ with each increment of blowing is the highest is referred to as the separation control region ${ }^{12}$. The separation control region is where the jet separation point is quickly moved to the trailing edge of the flap as blowing is increased. For $\alpha=0^{\circ}, C_{\mu}<0.05$ characterizes this region. Beyond separation control is the super circulation region. Here, lift continues to increase but it is not as efficient because the jet separation point has been fixed at the trailing edge of the dual radius flap.

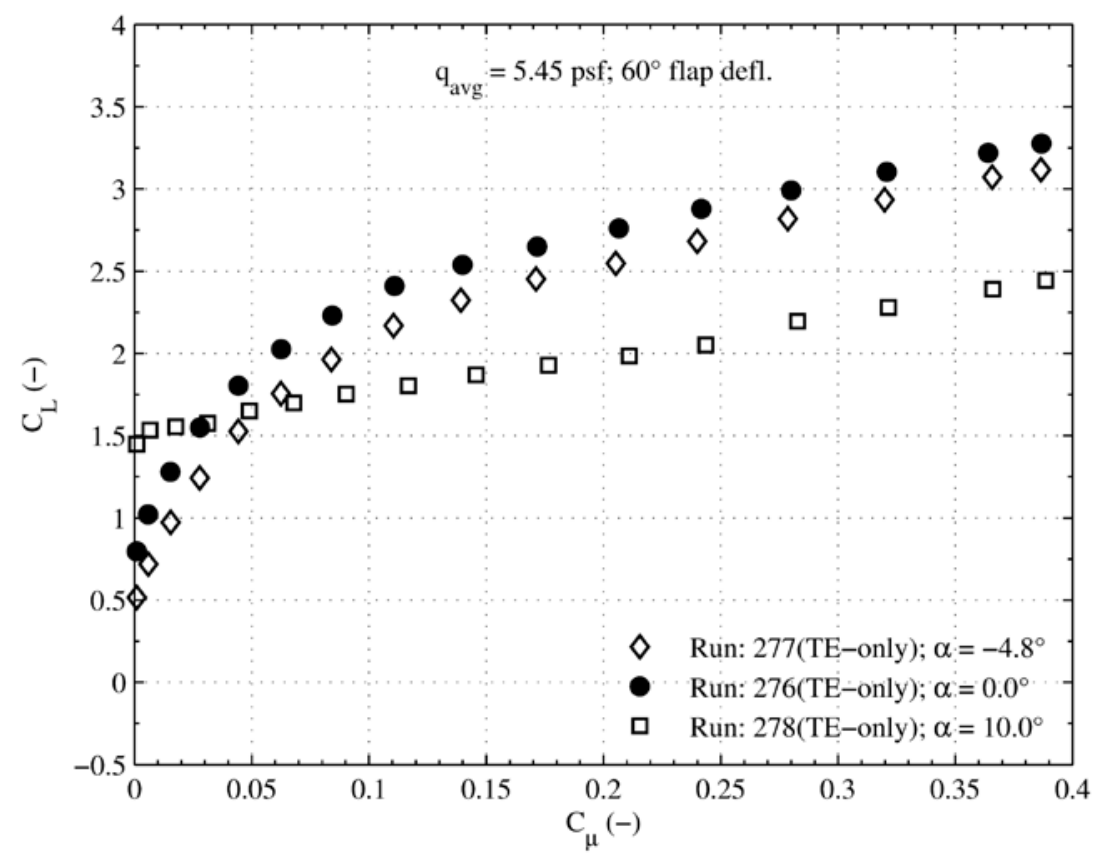

Figure 14. Effect of trailing edge blowing on model performance. $q_{\infty}=5.5 \mathrm{ps} f, 60^{\circ}$ flap deflection.

Figure 15 presents clean wing model performance at the maximum slot power setting, as augmented by flap deflection. Lift curve data shows the $80^{\circ}$ flap to be ineffective at high angles of attack. At $40 \mathrm{KTS}$, the $80^{\circ}$ flap stalls and has a lower maximum $C_{L}$ compared to the $60^{\circ}$ flap. As freestream speed increases, the $80^{\circ}$ flap becomes less effective across the entire angle of attack range. At the low speeds this result is not entirely expected as early predictions and previous work suggested a nearly constant offset between all flap deflections ${ }^{6}$. Figure 16 presents these alpha sweeps with the TPS-on. Here, the $80^{\circ}$ flap cannot maintain lift augmentation over the $60^{\circ}$ flap at high blowing and angle of attack. The noted stall suggests that the low pylon isn't overly strong at deflecting engine exhaust at the $80^{\circ}$ flap deflection. 


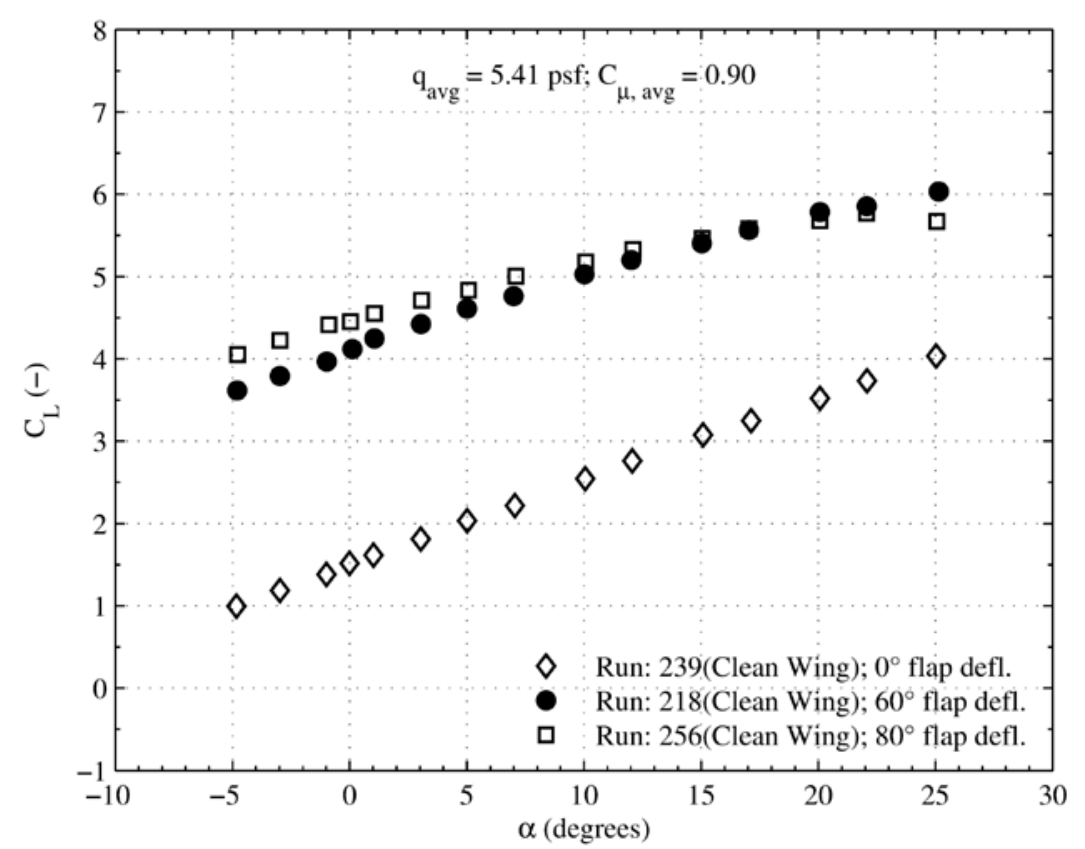

Figure 15. Effect of increasing flap deflection on clean wing configuration performance. $q_{\infty}=5.4 \mathrm{psf}, C_{\mu}=0.90$.

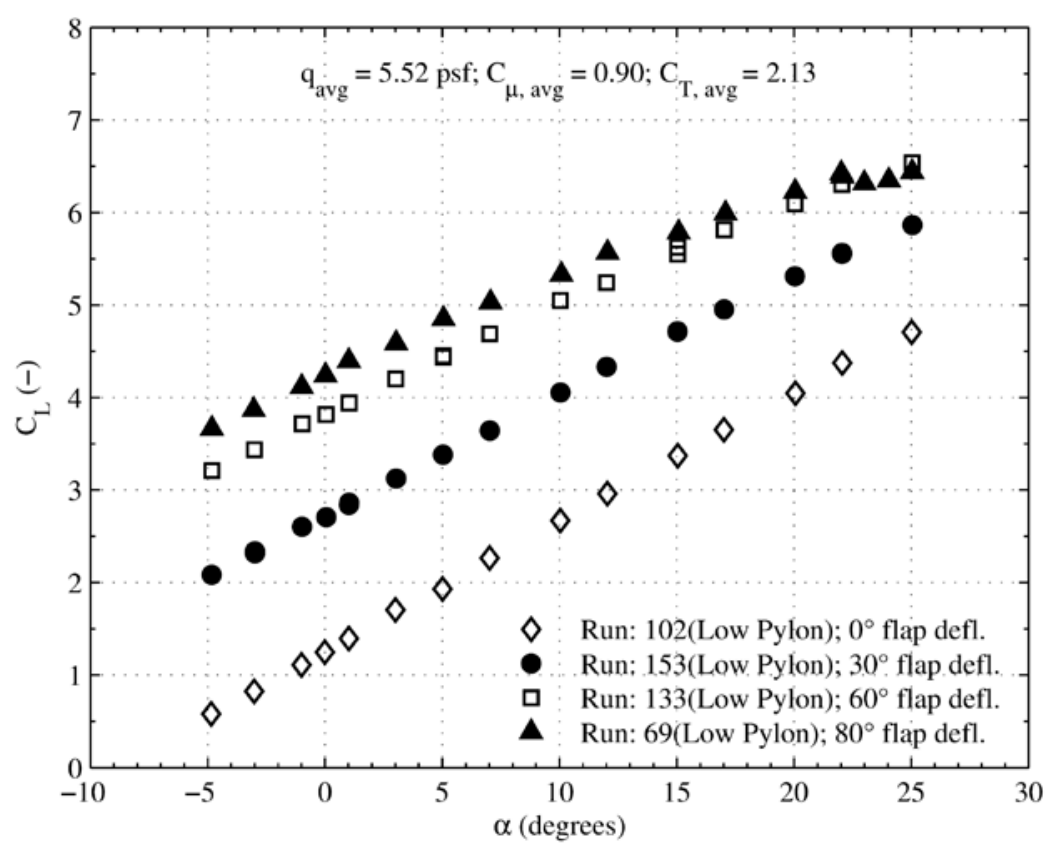

Figure 16. Effect of increasing flap deflection on low pylon configuration performance. $q_{\infty}=5.5 \mathrm{psf}, C_{\mu}=0.90, C_{T}=2.13$. 
Figure 17 examines the effects of variations in the powered-lift matrix and their effect on lift performance at a fixed tunnel speed and flap deflection. The powered-lift matrix represents variations in the slot and TPS power setting, defined by: 1) slots off and TPS off, 2) slots off and TPS maximum, 3) maximum slots and TPS off, 4) maximum slots and TPS maximum. The multiple curves in the figure illustrate the build-up effect that the poweredlift matrix points have on model performance. It is seen that the engine-on does contribute to higher lift. Performance benefits from this increased engine exhaust deflection are primarily noticed at high angles of attack, though. For the $60^{\circ}$ flap deflection at $40 \mathrm{KTS}$, the application of engine thrust is responsible for an increase in the maximum lift coefficient of greater than 1 . Again, the application of thrust increases the lift curve slope due to the $C_{T}{ }^{*} \sin \left(\alpha+\delta_{j e t}\right)$ component in the data. The increase in lift is not so much due to the thrust deflection angle, but more so the increased upper surface velocities that result from deflecting the engine exhaust onto the wing upper surface. Other general trends for like data sets show increased freestream speed and increased flap deflection contributing to earlier stall. Figure 18 shows the effect of the powered-lift matrix for the $60^{\circ}$ flap deflection at $100 \mathrm{KTS}$. It is seen that the addition of engine thrust, though it does contribute to higher lift and delayed stall, is not enough to prevent stall. A point to note is a comparison of the lift curves when $C_{\mu}=0$. The wing seems to stall, noted by the leveling off between $\alpha=7^{\circ}$ and $\alpha=10^{\circ}$, followed by a sharp increase in lift generation. It is believed that the deflected engine exhaust velocities are responsible for this effect, but the flow physics are not entirely understood.

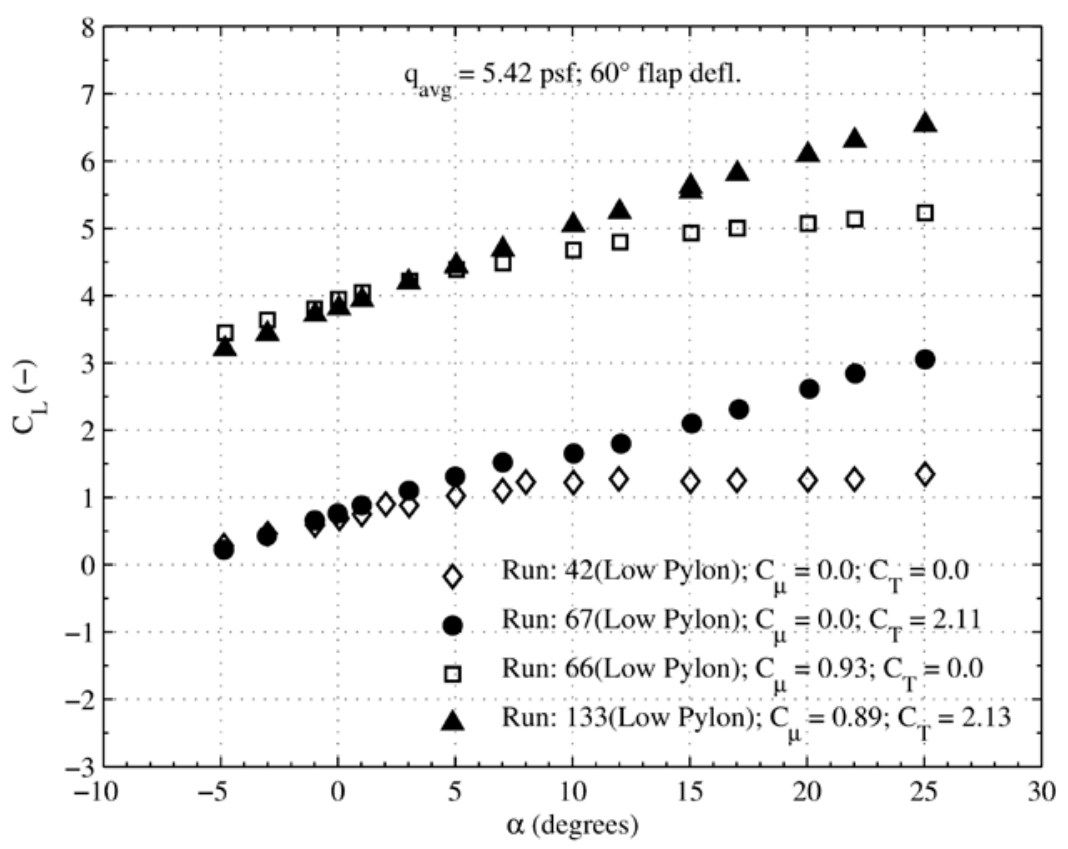

Figure 17. Powered-lift matrix model performance for the low pylon configuration. $q_{\infty}=5.4 \mathrm{psf}, 60^{\circ}$ flap deflection. 


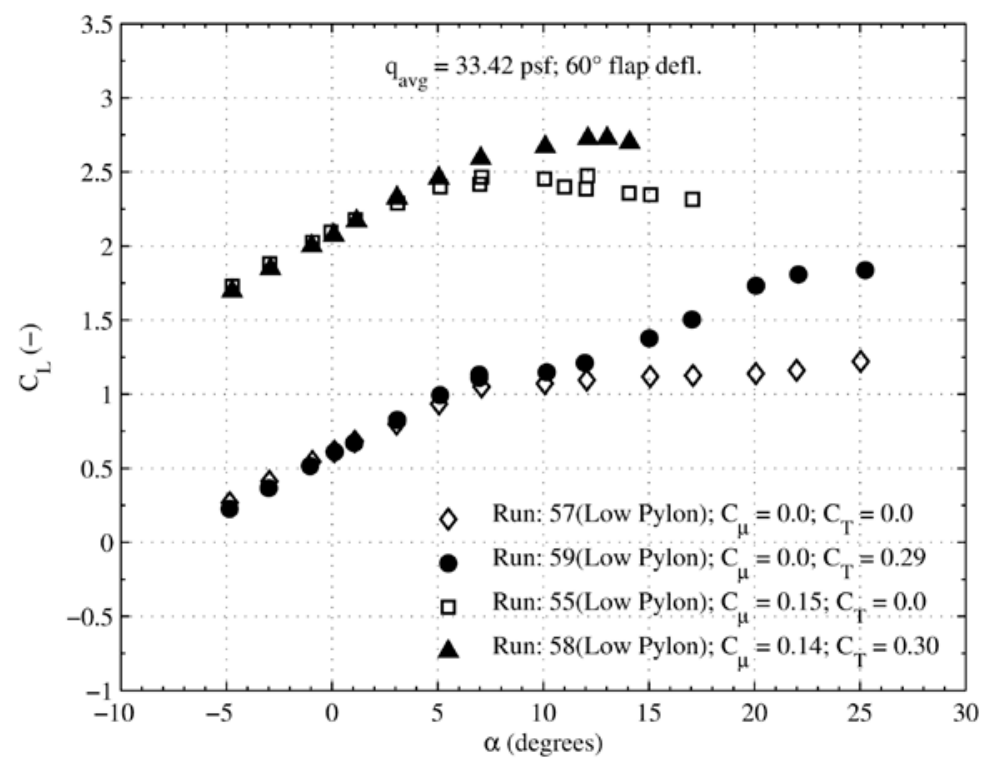

Figure 18. Powered-lift matrix model performance for the low pylon configuration. $q_{\infty}=33.4 \mathrm{psf}, 60^{\circ}$ flap deflection.

Figure 19 presents data from a sweep of TPS power setting at a constant momentum coefficient. This sweep was conducted differently than others; in this sweep, the model was held at a fixed angle of attack and data points were taken at 3 different values of thrust coefficient before pitching to the next angle. Thrust coefficients correspond to 0 , $2 / 3$, and full RPM conditions. The figure shows that engine-on does contribute to higher lift and prevents stall to beyond $\alpha=25^{\circ}$. It is seen that going from the 2/3 RPM setting $\left(C_{T}=1.45\right)$ to the maximum RPM setting $\left(C_{T}=\right.$ 2.11) provides only slightly better lift performance though; $\Delta C_{L}=0.35$ for $\Delta C_{T}=0.66$. At $60 \mathrm{KTS}$ and $80^{\circ}$ flap deflection, Fig. 20 shows a similar benefit to $C_{L}$ provided by the TPS. ( $C_{T}=0.24$ corresponds to the $20 \%$ RPM setting and $C_{T}=0.90$ corresponds to the maximum RPM setting.) Though this increased engine deflection does account for a delay in stall of $4^{\circ}$ at a $\Delta C_{L}=0.5$, it is not enough to prevent stall entirely. Note the alpha sweeps in Fig. 20 were acquired in the more typical way described in the Summary of Test Conditions section.

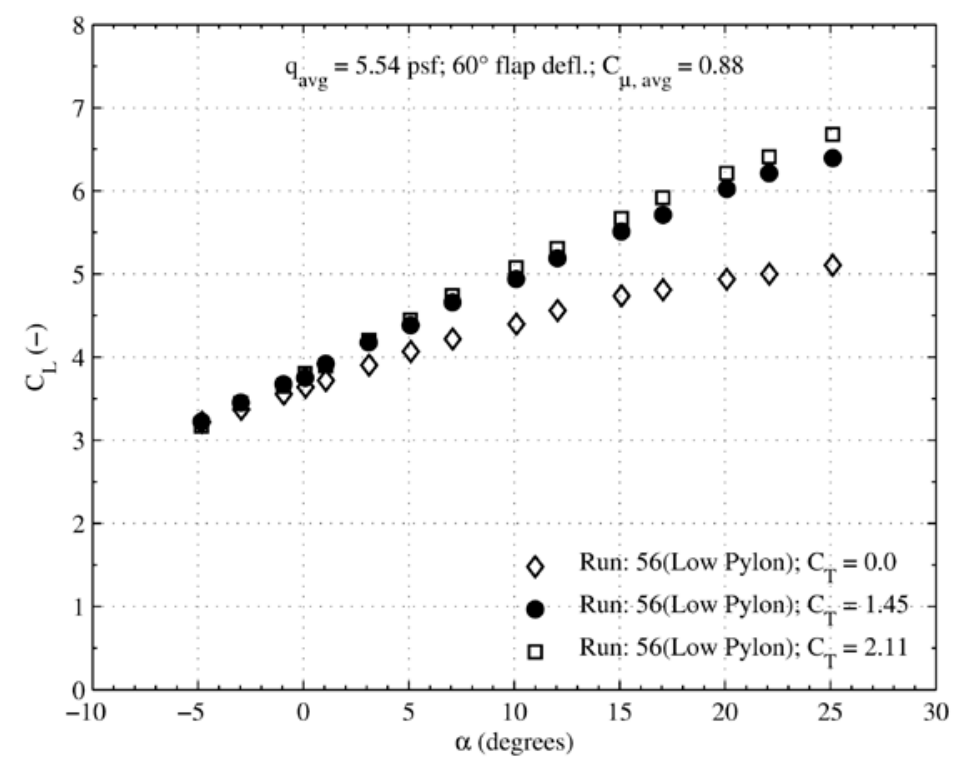

Figure 19. Effect of variations in thrust coefficient on model performance. $q_{\infty}=5.5 \mathrm{psf}, 60^{\circ}$ flap deflection. 


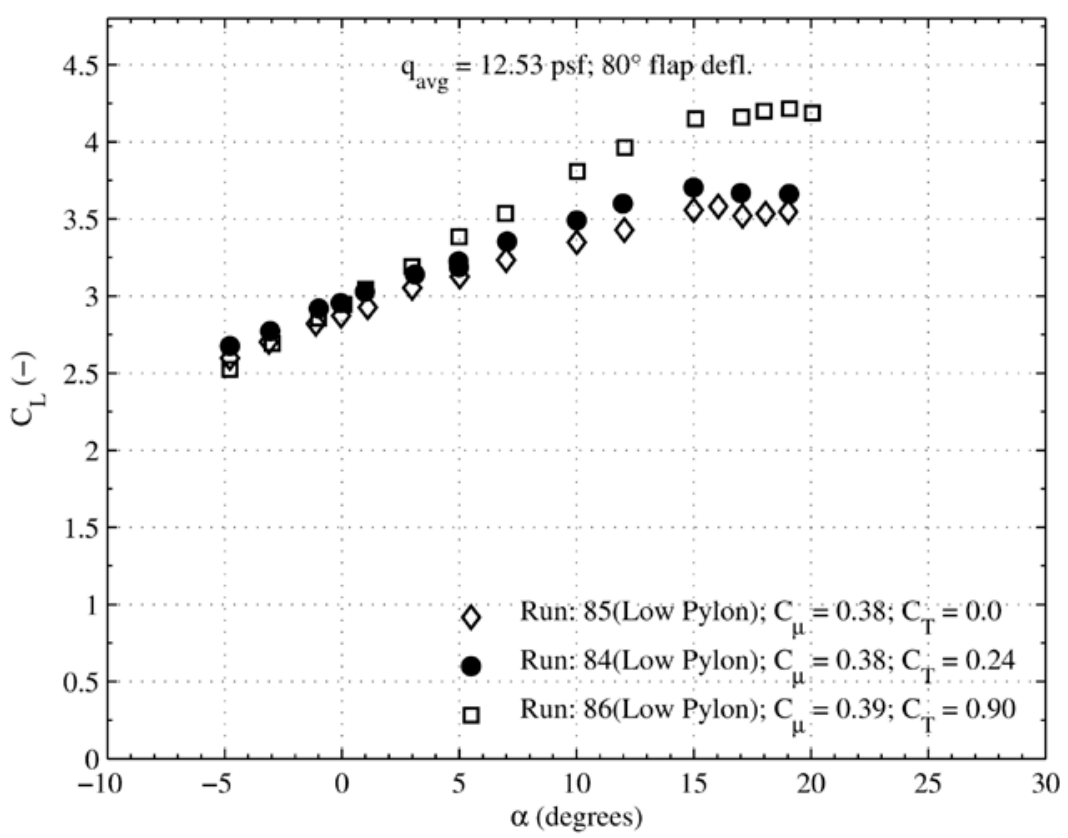

Figure 20. Effect of variation in thrust coefficient on model performance. $q_{\infty}=12.5$ psf, $80^{\circ}$ flap deflection.

Testing at the high and low pylon heights was intended to characterize the highly coupled circulation control wing and over-the-wing mounted engines. Figure 21 presents lift curves for the high and low pylon heights at 40 KTS and $80^{\circ}$ flap deflection. The data shows higher lift across the angle of attack range in the high pylon configuration. For this low speed, this result is not entirely expected; for a constant $C_{\mu}=0.9$, the low pylon height should deflect more engine exhaust, creating greater lift and better performance at high angles of attack. The greater lift curve slope for the low pylon height suggests there is a greater thrust component present in the lift data which would seem to support the expected result. Drag data, though, does not support this as there are negligible differences between the pylon heights. Higher drag in the low pylon would indicate more scrubbing drag due to increased exhaust deflection. Wing pressures on the TPS centerline show unremarkable differences between the pylon heights at the above conditions. At higher tunnel speeds, the differences in pylon height become less noticeable and the aerodynamic data tend to fall on top of each other. At higher speeds this can be explained by a fixed mass flow rate between the three tested tunnel speeds - as $q_{\infty}$ increases, $C_{\mu}$ decreases. Because the relationship between increased engine exhaust deflection is tightly coupled to the value of $C_{\mu}$, without more mass flow rate or increased jet velocity, the expected trends are not seen for the lower values of $C_{\mu}$. 


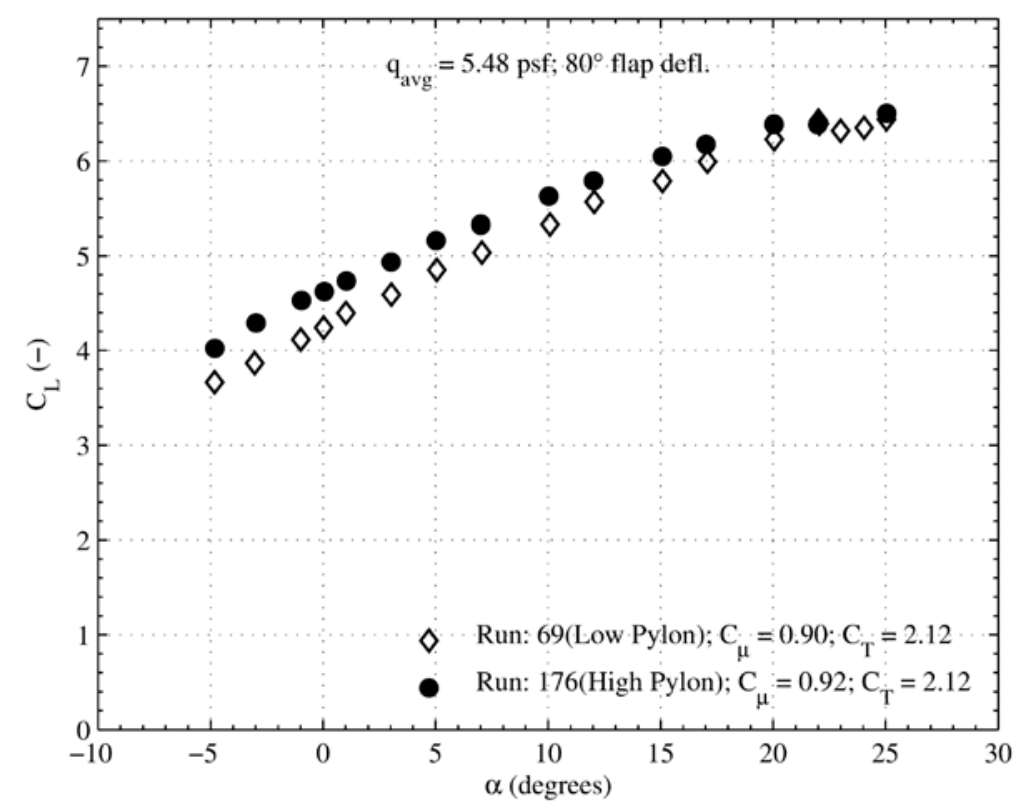

Figure 21. Performance of high and low engine pylon heights at high blowing rate. $q_{\infty}=5.5 \mathrm{psf}, 80^{\circ}$ flap deflection.

A comparison of the model configurations, with each component at its respective maximum power setting, is shown in Fig. 22. The figure shows how each model configuration adds to the baseline unpowered performance. It is seen that the addition of leading edge blowing is able to delay wing stall to greater than $25^{\circ}$ angle of attack. The maximum lift coefficient is increased from 3 to over 6 with the addition of leading edge blowing. With the application of thrust there is an increase in the lift curve slope, illustrating the effect of the thrust component in the data.

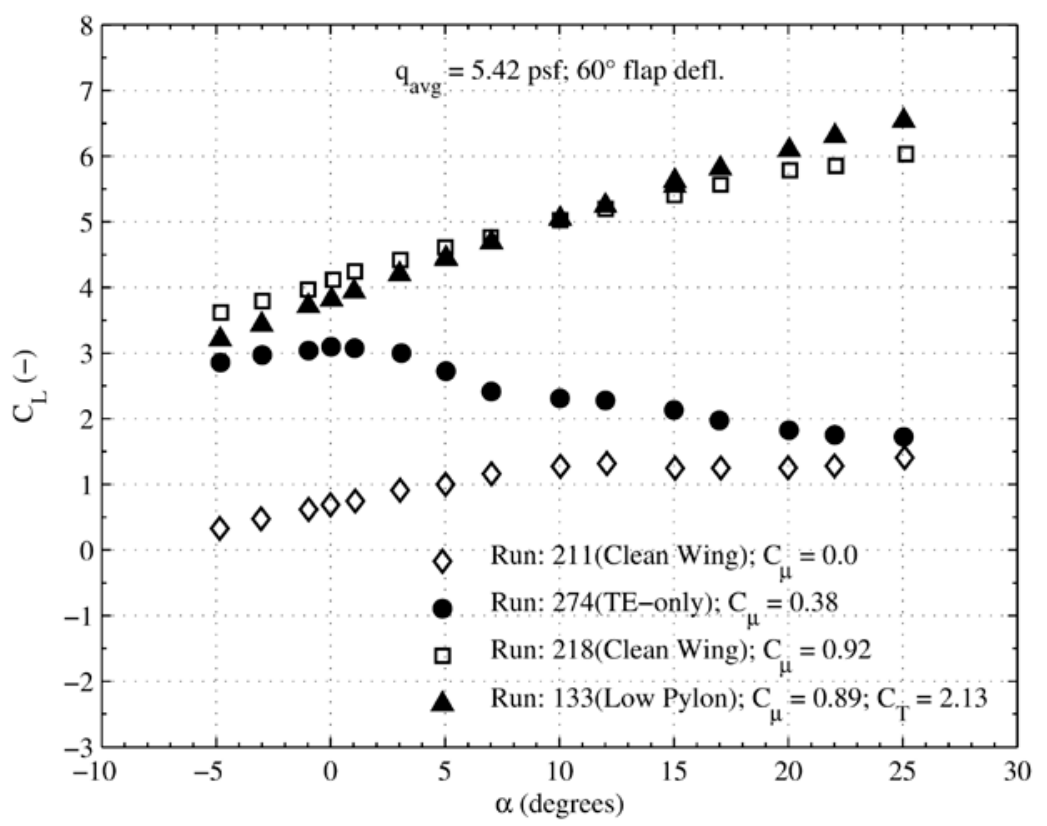

Figure 22. Model configuration performance. $q_{\infty}=5.4 \mathrm{psf}, 60^{\circ}$ flap deflection. 
The impact of leading edge blowing on the wing pressure profiles is presented at $\alpha=0^{\circ}$ and $\alpha=25^{\circ}$ in Fig. 23 and 26. Figures 23-24 shows data for the inboard most pressure port row and Figs. 25-26 shows data for the pressure port row located at the middle of the outboard wing. The test section dynamic pressure is $5.4 \mathrm{psf}$ and the $60^{\circ}$ flap deflection is attached; the plots are individually annotated with the local critical pressure coefficient for sonic flow, $C_{P}{ }^{*}$. At $25^{\circ}$ angle of attack, the inboard wing section is producing lift for both TE-only and combined blowing configurations. The wing section at $\eta=0.18$ is an unblown wing section, meaning this section is inboard of the wing plenums. Despite the unblown wing section, pressure profiles are still affected by blowing. Increased velocities from leading edge blowing contribute to higher lift - when leading edge blowing is present the flow is across the wing due to the flow direction being normal to the slot face. Looking to Figs. 25-26 at the outboard wing section, $\eta=$ 0.76 , the onset of wing stall is seen. As the angle of attack increases to $25^{\circ}$, the high streamline inflow angle causes stall to occur without the additional blowing momentum at the leading edge. The additional momentum from the leading edge blowing contributes to lift generation at low and high angles of attack as the flow maintains attachment through the acceleration around the nose. Note the remarkably negative $C_{P}$ values. This is due to the ratio of the dynamic pressure between the local slot flow and the freestream flow; the slot flow is nearly sonic, while the freestream flow is less than 0.15 Mach.

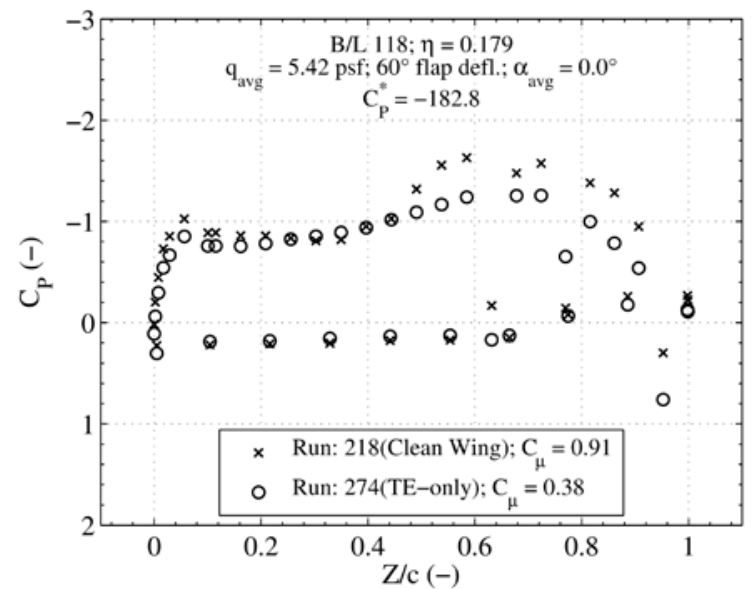

Figure 23. Inboard wing section pressure coefficient. $\alpha=0^{\circ}, q_{\infty}=5.4 \mathrm{psf}, 60^{\circ}$ flap deflection.

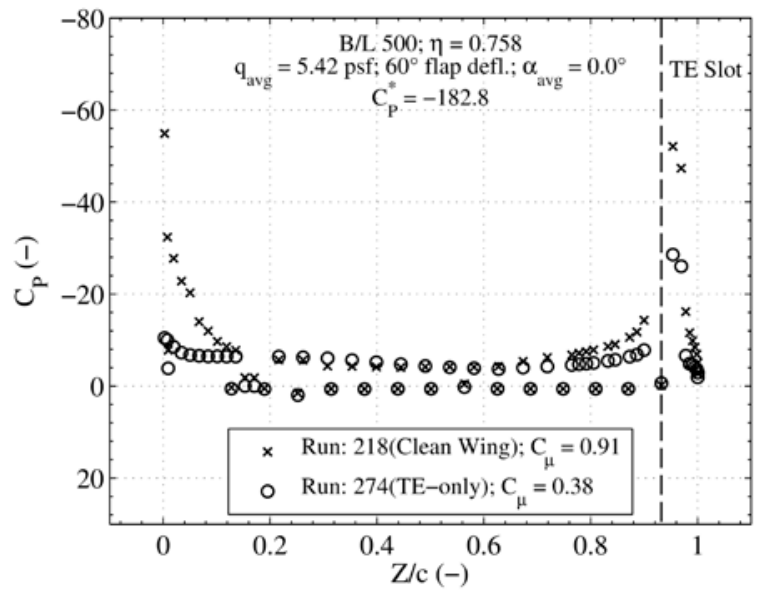

Figure 25. Outboard wing section pressure coefficient. $\alpha=0^{\circ}, q_{\infty}=5.4 \mathrm{psf}, 60^{\circ}$ flap deflection.

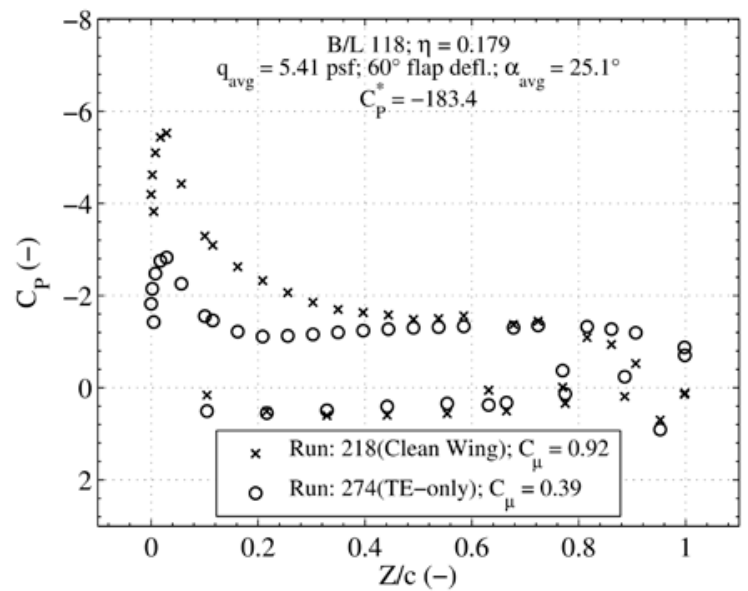

Figure 24. Inboard wing section pressure coefficient. $\alpha=25^{\circ}, q_{\infty}=5.4 \mathrm{psf}, 60^{\circ}$ flap deflection.

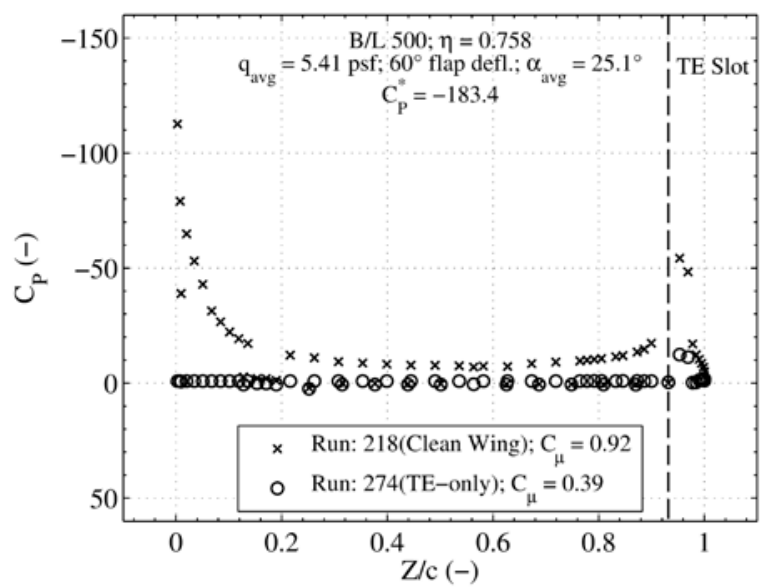

Figure 26. Outboard wing section pressure coefficient. $\alpha=25^{\circ}, q_{\infty}=5.4 \mathrm{psf}, 60^{\circ}$ flap deflection. 


\section{Conclusions}

The preceding discussion served to provide a summary of the test results from the recently completed AMELIA wind tunnel test. Please refer to the upcoming NASA technical memo for a more detailed discussion and presentation of the experimental results ${ }^{24}$.

This test is the first large-scale full-span wind tunnel model of its kind. All of the pre-test objectives were met, including 10 critical test points. The test data provides low-speed experimental force and moment data, model surface pressures, smoke and oil flow visualization, acoustic measurements, and skin friction data. The test data is open source and is intended to generate validation data for the CFD and acoustic modeling communities. The data generated from the test should provide a wealth of new data for modelers attempting to validate the tools used to design the next generation commercial transport.

Testing of the Cal Poly model proved successful and was the culmination of a 5-year NASA Research Announcement funded by the Fundamental Aeronautics Program. Testing was completed in 4 different model configurations, including 2 engine pylon heights. Test data showed that in order to achieve significant lift augmentation and sufficient angle of attack performance, leading edge blowing is needed. Without leading-edge blowing, stall occurred at low angles of attack and was more harsh than when leading-edge blowing is present. Testing saw little to no improvement gained using the $80^{\circ}$ flap deflection over the $60^{\circ}$ flap. Whereas, it was expected that a higher flap deflection would result in both increased lift and drag, only an increase in drag was seen. Testing also did not show the expected coupling between the CCW and over-the-wing mounted engine simulators. It was expected that the lower engine height would result in increased lift and high angle of attack performance, but test data showed no significant impact on the aerodynamic data.

Though this test did produce a multitude of new data for the CFD community to validate tools and improve the ability to predict performance for these types of configurations, future suggestions for work can build on this already expansive data set. As with any test intended for CFD, more detailed flow field measurements can complement the data set. Isolated leading edge blowing data to compliment the isolated trailing edge blowing data sets. Though not discussed here, the test data showed a strong coupling between blowing and pitch moment. A better understanding of the contribution from the leading edge slots alone would allow for a more optimum blowing configuration to be assessed.

\section{Acknowledgments}

The wind tunnel test and all supporting works have been sponsored by NASA's Subsonic Fixed Wing Program, NASA Research Announcement contract \#NNL07AA55C. Thank you to Craig Hange and Clif Horne for serving as the technical advisors. Special thanks to Mike Rogers for his continued support throughout the project. This project was largely a collaborative effort and the contributions from Greg Jones, Bob Englar, and the rest of the GTRI team are recognized. The support of the staff at the NFAC is also much appreciated. The success of this test can largely be attributed to the help and technical expertise of the Fluid Mechanics Laboratory at NASA Ames Research Center, specifically Rabi Mehta, Rob Fong, Jim Ross, Nate Burnside, Kevin James, Ted Garbeff, and Barry Porter. A special thank you to Mr. Fong, for whom we owe a large debt of gratitude. Lastly, thank you to the last member of the test team, Bobby Ehrmann.

\section{References}

${ }^{1}$ Zuk, J., Callaway, R. K., and Wardwell, D. A., “Adaptive Air Transportation System - A Catalyst for Change,” AIAA Paper 2002-5956, November, 2002.

${ }^{2}$ Marshall, D. D., and Jameson, K. K., “Overview of Recent Circulation Control Modeling Activities at Cal Poly,” AIAA Paper 2010-348, January, 2010.

${ }^{3}$ Johnson, P. L., Jones, K. M., and Madson, M. D., "Experimental Investigation of a Simplified 3D High Lift Configuration in Support of CFD Validation,” AIAA Paper 2000-4217, August, 2000.

${ }^{4}$ Jones, G. S., et al., “Overview of CFD Validation Experiments for Circulation Control Applications at NASA,” International Powered Lift Conference, Royal Aeronautical Society, July, 2008.

${ }^{5}$ Englar, R. J., Jones, G. S., Allan, B. G., and Lin, J. C., “2-D Circulation Control Airfoil Benchmark Experiments Intended for CFD Code Validation,” AIAA Paper 2009-902, January, 2009.

${ }^{6}$ Englar, R. J., Gaeta, R. J., Lee, W. J., and Leone, V., "Development of Pneumatic Over-the-Wing Powered-Lift Technology; Part I: Aerodynamic/Propulsive,” AIAA Paper 2009-3942, June, 2009.

${ }^{7}$ Pfingsten, K. C., Radespiel, R., “Experimental and Numerical Investigation of a Circulation Control Airfoil,” AIAA Paper 2009-533, January, 2009.

${ }^{8}$ Cagle, C. M., Jones, G. S., “A Wind Tunnel Model to Explore Unsteady Circulation Control for General Aviation Applications,” AIAA Paper 2002-3240, June, 2002. 
${ }^{9}$ Wetzel, D., Griffin, J., Liu, F., and Cattafesta, L., “An Experimental Study of a Circulation Control Airfoil Trailing Edge Flow Field,” AIAA Paper 2010-4576, June, 2010.

${ }^{10}$ Collins, S. W., Westra, B. W., Lin, J. C., Jones, G. S., and Zeune, C. H., "Wind Tunnel Testing of Powered Lift, All-Wing STOL Model,” The Aeronautical Journal, Vol. 113, No. 1140, February, 2009, pp. 129-137.

${ }^{11}$ Lin, J. C., et al., "Flow-Field Measurement of a Hybrid Wing Body Model with Blown Flaps,” AIAA Paper 2008-6718, August, 2008.

${ }^{12}$ Milholen, W. E. II, Jones, G. S., Chan, D. T., Goodliff, S. L., "High-Reynolds Number Circulation Control Testing in the National Transonic Facility,” AIAA Paper 2012-0103, January, 2012.

${ }^{13}$ Jameson, K. K., et al., "Design and Wind Tunnel Testing of Cal Poly's AMELIA 10 Foot Span Hybrid Wing-Body Low Noise CESTOL Aircraft," 27 $7^{\text {th }}$ International Congress of the Aeronautical Sciences, September, 2010.

${ }^{14}$ Alley, N. R, Steele, J., Neidhoefer, J. C., Englar, R. J., and Blaylock, G., "Development of a Cruise-Efficient ExtremeSTOL-Capable Demonstrator UAV,” AIAA Paper 2010-3450, April, 2010.

${ }^{15}$ Paciano, E. N., Lichtwardt, J. A., Jameson, K. K., Marshall, D. D., and Fong, R. K., "Flow Uniformity Calibration of AMELIA’s Circulation Control Wings,” AIAA Aerospace Sciences Meeting, AIAA Paper 2013-0975, January, 2013.

${ }^{16}$ Ehrmann, R. S., "Development of Measurement Methods for Application to a Wind Tunnel Test of an Advanced Transport Model,” Master’s Thesis, Aerospace Engineering Dept., California Polytechnic State University, San Luis Obispo, CA, 2010.

${ }^{17}$ van Aken, J. M., and Yang, L., "Development of a new State-of-the-Art Data Acquisition System for the National FullScale Aerodynamics Complex Wind Tunnels,” AIAA Paper 2009-1346, January, 2009.

${ }^{18}$ Burnside, N. J., and Horne, W. C., "Acoustic Surveys of a Scaled-Model CESTOL Transport Aircraft in Static and Forward Speed Conditions,” AIAA Paper 2012-2231, June, 2012.

${ }^{19}$ AIAA, “Nomenclature and Axis Systems for Aerodynamic Wind Tunnel Testing,” AIAA Guide, G-129-2012, 2012.

${ }^{20}$ Zell, P. T., Flack, K., "Performance and Test Section Flow Characteristics of the National Full-Scale Aerodynamics Complex 40- by 80-Foot Wind Tunnel,” NASA TM-101065, 1989.

${ }^{21}$ Braslow, A. L., and Knox, E. C., "Simplified Method for Determination of Critical Height of Distributed Roughness particles for Boundary-Layer Transition at Mach Numbers from 0 to 5,” NACA TN-4363, 1958.

${ }^{22}$ Wahls, R. A., Adcock, J. B., Witkowski, D. P., and Wright, F. L., “A Longitudinal Aerodynamic Data Repeatability Study for a Commercial Transport Model Test in the National Transonic Facility,” NASA TP-3522, 1995.

${ }^{23}$ AIAA, “Assessment of Experimental Uncertainty with Application to Wind Tunnel Testing," AIAA Standard, S-071A1999, 1999.

${ }^{24}$ Marshall, D. D., Jameson, K. K., Fong, R. K., Lichtwardt, J. A., and Paciano, E. N., “AMELIA Technical Memorandum,” NASA Ames Research Center, January, 2013 (to be published). 